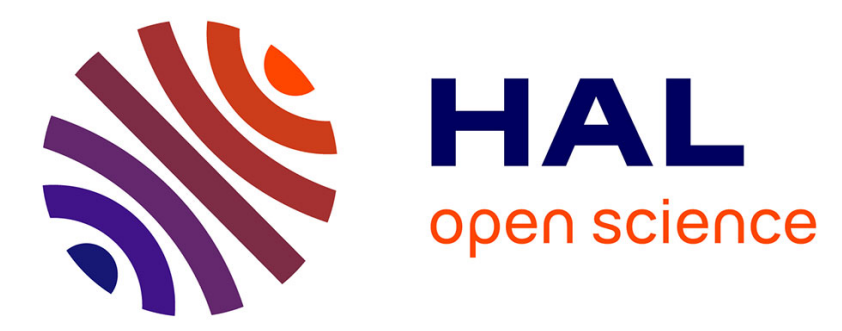

\title{
Polymer dynamics in thin p-type conducting films investigated by ac-electrogravimetry. Kinetics aspects on anion exclusion, free solvent transfer, and conformational changes in poly(o-toluidine)
}

Jeronimo Agrisuelas, Claude Gabrielli, J.J. García-Jareño, Hubert Perrot, Ozlem Sel, F. Vicente

\section{To cite this version:}

Jeronimo Agrisuelas, Claude Gabrielli, J.J. García-Jareño, Hubert Perrot, Ozlem Sel, et al.. Polymer dynamics in thin p-type conducting films investigated by ac-electrogravimetry. Kinetics aspects on anion exclusion, free solvent transfer, and conformational changes in poly(o-toluidine). Electrochimica Acta, 2015, 153, pp.33-43. 10.1016/j.electacta.2014.11.159 . hal-01110553

\author{
HAL Id: hal-01110553 \\ https://hal.science/hal-01110553
}

Submitted on 18 Feb 2015

HAL is a multi-disciplinary open access archive for the deposit and dissemination of scientific research documents, whether they are published or not. The documents may come from teaching and research institutions in France or abroad, or from public or private research centers.
L'archive ouverte pluridisciplinaire HAL, est destinée au dépôt et à la diffusion de documents scientifiques de niveau recherche, publiés ou non, émanant des établissements d'enseignement et de recherche français ou étrangers, des laboratoires publics ou privés. 
Polymer dynamics in thin p-type conducting films investigated by acelectrogravimetry. Kinetics aspects on anion exclusion, free solvent transfer, and conformational changes in poly(o-toluidine).

J. Agrisuelas*,1, C. Gabrielli' ${ }^{2,3}$, J. J. García-Jareño ${ }^{1}$, H. Perrot ${ }^{2,3}$, O. Sel $^{2,3}$ and F.

Vicente ${ }^{1}$

${ }^{1}$ Departament de Química Física, Universitat de València. C/ Dr. Moliner, 50, 46100, Burjassot, València, Spain.

2 Sorbonne Universités, UPMC Univ Paris 06, UMR 8235, Laboratoire Interfaces et Systèmes Electrochimiques, F-75005, Paris, France.

${ }^{3}$ CNRS, UMR 8235, LISE, F-75005, Paris, France.

*E-mail: jeronimo.agrisuelas@uv.es 


\begin{abstract}
A new transfer model is proposed to explain $a c$-electrogravimetry response of pdoped films. This model takes into account the exclusion effect occurring as a result of the anion transfer. The insertion/expulsion of anions inside a film involves simultaneously the expulsion/insertion of free solvent molecules. The number of solvent molecules excluded depends on the volume of anion transferred. Solvent transfer stimulated by the conformational changes of films constitutes the remaining electrogravimetric response when the exclusion process cannot explain by itself this response. Consequently, the kinetics of this free solvent transfer can be directly related to the kinetics of conformational changes. This model was validated in poly(o-toluidine) thin films where electrochemical kinetics were quantitatively investigated as a function of the applied potential. As far as we know, for the first time, charge transfer and conformational changes could be kinetically separated. This new transfer model may respond to fundamental questions on the electrochemistry of conducting polymers, which may have a significant impact on a large number of applications.
\end{abstract}

Keywords: Intrinsically conducting polymer, Electrochemical quartz crystal microbalance, Electrochemical impedance spectroscopy, ac-Electrogravimetry, Conformational changes. 


\section{Introduction}

In order to convert conceptual and experimental findings to practical and relevant technological devices based on intrinsically conducting polymers (ICPs), several parameters should be optimized (molecular structure or solvent-electrolyte medium among others)[1,2]. The conduction mechanism and the electrolyte as a counter ion source have received substantial attention[3,4]. Inevitably, ICPs immersed in aqueous or non-aqueous solutions entail the transfer of solvent molecules in permselective conditions. This aspect is taken into account either qualitatively or quantitatively but the studies are commonly restricted to overall electrochemical process. Specially, Hillman and coworkers have extensively studied the mobile species transfer processes with the intention of achieving a deeper understanding on the redox dynamics of ICPs (spatial distributions, viscoelasticity, solvent effect, mechanisms)[5-10].

Solvent inside the films acts as a plasticizer, lubricating the inter-molecular motions and relaxing the film. The inner solvent matrix of a polymeric film can be divided in two kinds of populations: molecules intimately bound to polymeric structure and free molecules. The amount of free molecules changes during the charge/discharge process of the polymer by the transfer between the polymer and solution. The extent of solvent transfer depends on the solution composition and it does not require to have integer stoichiometry coefficients[5]. The influence of solvent transfer requires a good understanding and quantification in technological applications where the polymer film is in contact with a liquid phase. For example, the driven volume variation in biomimetic gel motors depends on the number of counterions and solvent molecules exchanged during the electrochemical reactions[11].

Solvent transfer can be due to different electrochemical-driving forces in $\operatorname{ICPs}[5,12,13]:$ i) Donnan equilibrium to maintain equal chemical potentials inside and outside of the film, $i$ ) changes of the volume in the hydration matrix inside the film owing to ion movements or iii) changes in the macromolecular structure of the reactive polymer, conformational motions. Although there is no a priori relationship with the injected charge and the non-charged molecules, neutral solvent transfer can be expected to be controlled by a non-ideal thermodynamic behavior (non-linear film solvation with charge state) $[14,15]$. As an example, this control can take place in films where slower electronic transfer along dynamic chains introduces a slow conformational change with slow noncharged species transfer. However, under specific experimental conditions or for very 
thin films, the transfer of neutral solvent can be kinetically controlled (although "indirectly") because both insertion/expulsion of ions and movements of polymeric backbones (both kinetically controlled) have a "direct" effect on the solvent transfer[16,17]. In the view of that, the transfer of neutral solvent, or in other words, the hydration extent of ICPs could be modulated varying the oxidation state via an external potential.

The main difficulty in the study of solvent transfers during electrochemical reaction in ICPs is the neutral character of these molecules. For these reasons, complementary techniques should be used together with electrochemical techniques like quartz crystal microbalance to detect mass changes in the polymeric film or probe beam deflection to detect concentration gradients of species transfer close to the polymer|solution interface[18-21].

In this paper, $a c$-electrogravimetry is used to characterize ions and solvent transfer in the polymer|solution interface. This technique was clearly proven to be helpful in polymer studies as an easy and fast identification methodology for cation and anion transfers involved in the charge compensation process together with a noticeable kinetic information when electrochemical and mass impedance spectroscopy are discussed together[22-26]. To separate among anion, cation and solvent contributions from the global electrogravimetric response, it is necessary to find experimental conditions where the time constants of these three transfers are fairly different[27]. Experimentally, this situation is not always achieved, especially in complex electroactive systems.

A different strategy is to find an appropriate model and procedure for analyzing the experimental results. If that is found, isolated kinetic studies of solvent transfer can be performed by $a c$-electrogravimetry. As a first approximation, partial electrogravimetric responses can be mathematically obtained from the global response. An anion-solvent transfer can be analyzed if the cation contribution is eliminated. In a similar manner, if the anion contribution is eliminated, a partial cation-solvent transfer can be obtained[27,28]. Recently, the electrogravimetric response of the global free solvent transfer was separated from the electrogravimetric response of ions transfer[16,17].

Now, a refined procedure for the interpretation of $a c$-electrogravimetry results is proposed to study the anion p-doping of ICPs. Here, the anion exclusion effect is taken into account $[12,29,30]$. The anion insertion during the charge balance excludes a specific 
number of solvent molecules equivalent to the anion volume, which are expelled from the film during the oxidation. During the reduction, the free volume liberated by anions is rapidly occupied by a number of free solvent molecules equivalent to the anion volume. Therefore, other mass variations during the experiment should be due to the free solvent transfer owing to the formation/creation of free volume inside the film by chain motions or by accommodation of the charged species in the reactive polymer. Consequently, the kinetics of this free solvent transfer should be a "fingerprint" to the kinetics of conformational changes in the films. A priori, this theoretical approach allows both processes to be decoupled.

A perusal of the literature reveals that very few studies have directly addressed the kinetics of conformational changes of polymers; partly due to the difficulties reported about the appropriate techniques available. Recently, Otero and coworkers emphasized that conformational and structural magnitudes induced by electrochemical reactions are not included in the chemical kinetic model of ICPs[31,32]. They show an intense experimental procedure to explore the change of the intermolecular forces during the electrochemical reactions of polymers. The investigation of the global behavior took into account all the electrochemical processes involved between the modified electrode and the solution and the global behavior was explained through structure and thermodynamic phenomena (structural chemical kinetics).

The motivation of this work is to show a good approximation of the most physically realistic description of the system where ICP changes its volume to store inserted ions or solvent molecules by conformational arrangements during the electrochemical transitions[33-36]. A representative p-type ICP were chosen to test the applicability of the proposed model to a dynamic molecular system of technological importance in aqueous media and to explore quantitatively the dynamics of thin films. Recent works clearly prove that the poly(o-toluidine) (POT) is a good candidate[16,17]. POT is a polyaniline derivative where $-\mathrm{CH}_{3}$ group in the polymer backbone causes greater electron localization and interchain separation than polyaniline[37]. This fact favours the formation of two time-stable conducting forms with polarons or bipolarons. Moreover, literature clearly exhibits their increasing technological interest for this polymer in electrochromic devices[38], biofuel cell-based devices[39] or biosensors[40]. 


\section{Ac-electrogravimetry: Theory and background for anion exclusion in dynamic polymers}

During the redox reaction of a conducting polymer in aqueous or non-aqueous media, transfer of ionic species can compensate the excess or defect of charge inside a polymer film, eq (1), the universally accepted concept of coupled electron/ion transfer. Most conducting polymers $\langle\mathrm{P}\rangle$ lose electrons when the neutral chains are submitted to anodic potentials generating positive charges with consequent insertion of charge balancing anions from the solution (p-doping).

Often, the amount of free solvent molecules (not structural) inside a polymeric matrix is a function of the oxidation state of the polymer to satisfy osmotic and volume constraints[10]. The insertion of ionic molecules to balance the charge of the oxidized film involves the displacement of inner solvent molecules. In the simplest situation when the volume of the holes in the ionic channels remains constant like in rigid polymers, the amount of, for example, water molecules which can be expelled out from the film during the anion insertion depends on the volume of anions (Figure 1), therefore, $V_{\mathrm{A}^{-}}=n V_{\mathrm{H}_{2} \mathrm{O}}$. In a reverse process, free water molecules from solution can occupy the space left by anions during the anion expulsion. This fact is known as exclusion[12,30,41].

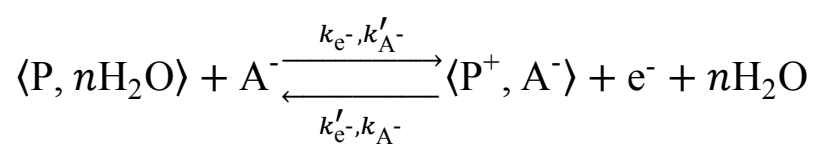

where $\left\langle\mathrm{P}, n \mathrm{H}_{2} \mathrm{O}\right\rangle$ is the hydrated polymer and $\left\langle\mathrm{P}^{+}, \mathrm{A}^{-}\right\rangle$is the polymer matrix doped with anions $\mathrm{A}^{-}, n$ being the number of free water molecules excluded during $\mathrm{A}^{-}$insertion. The parameters, $k_{\mathrm{A}^{-}}$and $k_{\mathrm{e}^{-}}$are the kinetic constants of anion and electron expulsion from polymer, respectively, whereas, the parameters $k_{\mathrm{A}^{-}}^{\prime}$ and $k_{\mathrm{e}^{-}}^{\prime}$ are the kinetic constants of anion and electron insertion to polymer, respectively.

By assuming that anions transport through very thin films and in electrolytes with high ionic strength are fast enough, the kinetic constants only depend on the resistance of anions to cross the polymer|solution interface[42,43]. Then, the kinetic constants of both electron and anion transfer are equal as follows $k_{\mathrm{e}^{-}}=k_{\mathrm{A}^{-}}^{\prime}$ and $k_{\mathrm{e}^{-}}^{\prime}=k_{\mathrm{A}^{-}}$.

Gabrielli et al. have extensively described that for very thin polymer films $[22,27,42-45]$, the change of the concentration of the anions, $\Delta C_{\mathrm{A}^{-}}$, when a small sine wave potential perturbation, $\Delta E$, is applied as a function of perturbation frequency is: 


$$
\frac{\Delta C_{\mathrm{A}^{-}}}{\Delta E}(\omega)=\frac{-G_{\mathrm{A}^{-}}}{j \omega d_{f}+K_{\mathrm{A}^{-}}}
$$

where $j=\sqrt{-1}, \omega$ is the angular frequency, which equals to $2 \pi f, f$ is the perturbation frequency, $d_{f}$ is the thickness of the polymer film,

$$
K_{\mathrm{A}^{-}}=k_{\mathrm{A}^{-}}+k_{\mathrm{A}^{-}}^{\prime} C_{\mathrm{A}^{-}}^{\text {sol }}
$$

and

$$
G_{\mathrm{A}^{-}}=-b_{\mathrm{A}^{-}} k_{\mathrm{A}^{-}}\left(C_{\mathrm{A}^{-}}-C_{\mathrm{A}^{-}}^{\text {min }}\right)+b_{\mathrm{A}^{-}}^{\prime} k_{\mathrm{A}^{-}}^{\prime}\left(C_{\mathrm{A}^{-}}^{\max }-C_{\mathrm{A}^{-}}\right) C_{\mathrm{A}^{-}}^{\text {sol }}
$$

where, $C_{\mathrm{A}^{-}}$is the concentration of $\mathrm{A}^{-}$in the polymer, $C_{\mathrm{A}^{-}}^{\max }$ is the maximum concentration of the sites available for the insertion in the polymer, $C_{\mathrm{A}^{-}}^{\text {min }}$ is the minimum concentration of the occupied sites and $C_{\mathrm{A}^{-}}^{\text {sol }}$ is the concentration of species in the solution. The parameters, $k_{\mathrm{A}^{-}}$and $k_{\mathrm{A}^{-}}^{\prime}$ are the above mentioned kinetic rate constants activated by potential, $\quad k_{\mathrm{A}^{-}}=k_{\mathrm{A}^{-} 00} \exp \left(b_{\mathrm{A}^{-}}\left(E-E^{0 \prime}\right)\right) \quad$ and $\quad k_{\mathrm{A}^{-}}^{\prime}=k_{\mathrm{A}^{-} 00} \exp \left(b_{\mathrm{A}^{-}}^{\prime}\left(E-E^{0 \prime}\right)\right)$, respectively where $E^{0 \prime}$ is the formal potential and $k_{\mathrm{A}^{-} 00}$ is a preexponential factor of the kinetic rate constants independent of applied potential $E$.

The parameters, $b_{\mathrm{A}^{-}}$and $b_{\mathrm{A}^{-}}^{\prime}$ are the Tafel coefficients related to the number of electrons $\left(n_{\mathrm{e}^{-}}\right)$involved in the faradaic process and the symmetry of direct and reverse transition with respect to the formal redox potential[46,47]:

$$
b_{\mathrm{A}^{-}}-b_{\mathrm{A}^{-}}^{\prime}=B_{\mathrm{A}^{-}}=\frac{n_{\mathrm{e}^{-}} F}{R T}
$$

where $R$ is the gas constant and $T$ is the absolute temperature.

In a more sophisticated and realistic model for anion p-doping of ICPs, electrochemical reactions induce conformational changes such as swelling, shrinking, compaction or relaxation processes owing to repulsive/attractive interactions inside the film or formation/destruction of molecular covalent bonds[32]. The reactive film could act like a molecular pump during a sinusoidal potential perturbation. Accordingly, a constant thickness of films cannot be considered since it may change depending on the polarization potential[33-35,48]. Eq (2) can be slightly modified in terms of surface concentration considering only a bidimensional surface[16,17]:

$$
d_{f} \frac{\Delta C_{\mathrm{A}^{-}}}{\Delta E}(\omega)=\frac{\Delta \Gamma_{\mathrm{A}^{-}}}{\Delta E}(\omega)=\frac{-G_{\mathrm{A}^{-}}}{j \omega+K_{\mathrm{A}^{-}}^{\prime}}
$$

where $K^{\prime}=K / d_{f}$ and, then, $j \omega d_{f}$ changes to $j \omega$.

Based on this model, eq (6) allows the theoretical electrochemical impedance, $\Delta E / \Delta I(\omega)$ to be calculated only for the involved anion transfer. Thus, 


$$
\frac{\Delta E}{\Delta I}(\omega)=R_{u}+\frac{1}{j \omega C_{d l}+\frac{1}{Z_{f}}}
$$

where $R_{u}$ is the uncompensated solution resistance, $C_{d l}$ is the double layer capacity and $Z_{f}$ is the faradaic impedance defined as:

$$
Z_{f}=\frac{1}{j \omega S F z_{\mathrm{A}^{-}}\left[\frac{G_{\mathrm{A}^{-}}}{j \omega+K_{\mathrm{A}^{-}}^{\prime}}\right]}
$$

where $z_{\mathrm{A}^{-}}$is the valence of the anion, $F$ is the Faraday constant, and $S$ is the active electrode surface area. Eq (8) is close to classical Randless equivalent circuit where the charge transfer resistance and the Warburg element were replaced by a simple $R, C$ circuit.

By subtracting the non-faradaic contributions, the electrical charge/potential transfer function, $\Delta q / \Delta E(\omega)$, can be calculated as:

$$
\frac{\Delta q}{\Delta E}(\omega)=\frac{1}{j \omega} \frac{1}{\frac{\Delta E}{\Delta I}(\omega)-R_{u}}-C_{d l}
$$

and by using the eq (7) and (6), this theoretical transfer function is equal to:

$$
\frac{\Delta q}{\Delta E}(\omega)=S F z_{\mathrm{A}^{-}}\left[\frac{G_{\mathrm{A}^{-}}}{j \omega+K_{\mathrm{A}^{-}}^{\prime}}\right]
$$

Here, non-charged species (free $\mathrm{H}_{2} \mathrm{O}$ ) do not participate in the charge balance but the insertion/expulsion of these molecules involves effective mass changes of the reactive film. Therefore, considering eq (6), the mass/potential transfer function, $\Delta m / \Delta E(\omega)$, is easily deduced to:

$$
\frac{\Delta m}{\Delta E}(\omega)=S\left(\delta_{\mathrm{A}^{-}} M_{\mathrm{A}^{-}}\left[\frac{G_{\mathrm{A}^{-}}}{j \omega+K_{\mathrm{A}^{-}}^{\prime}}\right]+n \delta_{\mathrm{H}_{2} \mathrm{O}} M_{\mathrm{H}_{2} \mathrm{O}}\left[\frac{G_{\mathrm{H}_{2} \mathrm{O}}}{j \omega+K_{\mathrm{H}_{2} \mathrm{O}}^{\prime}}\right]\right)
$$

where $M_{i}$ is the molar mass of the $i$ species involved $\left(\mathrm{A}^{-}\right.$or $\left.\mathrm{H}_{2} \mathrm{O}\right)$ and $K_{\mathrm{H}_{2} \mathrm{O}}^{\prime}$ and $G_{\mathrm{H}_{2} \mathrm{O}}$ have a similar meaning as eq (3) and (4), respectively. The parameter $\delta_{\mathrm{A}^{-}}$is +1 due to the increase of mass when the polymer is oxidized, eq (1). Accordingly, the $\delta_{\mathrm{H}_{2} \mathrm{O}}$ is -1 due to the decrease of mass resulting from the expulsion of free water molecules induced by the insertion of anions (exclusion).

In a rigid film, kinetics of free $\mathrm{H}_{2} \mathrm{O}$ transfer are governed by kinetics of anion transfer to satisfy volume constraints (Figure 1)[10]. Consequently, $G_{\mathrm{A}^{-}}=G_{\mathrm{H}_{2} \mathrm{O}}$ and $K_{\mathrm{A}^{-}}^{\prime}=K_{\mathrm{H}_{2} \mathrm{O}}^{\prime}$ can be easily assumed and, then, eq (11) is simplified to:

$$
\frac{\Delta m}{\Delta E}(\omega)=S\left(\delta_{\mathrm{A}^{-}} M_{\mathrm{A}^{-}}+n \delta_{\mathrm{H}_{2} \mathrm{O}} M_{\mathrm{H}_{2} \mathrm{O}}\right)\left[\frac{G_{\mathrm{A}^{-}}}{j \omega+K_{\mathrm{A}^{-}}^{\prime}}\right]
$$


In a reactive polymer with a constant thickness in all polarization potentials considering only the exclusion effect, the capacitive response would show a loop owing to a single electrochemical transfer (Figure 2a), in this case with charge balancing anions. On the contrary, the global electrogravimetric response depends on anion mass and anion volume. As an example, a loop in the first quadrant of the global electrogravimetric response would appear because the mass of one anion (in this case $80 \mathrm{~g} \mathrm{~mol}^{-1}$ ) is higher than the mass of four $(n=4)$ displaced water molecules (in this case $n M_{\mathrm{H}_{2} \mathrm{O}}=4 \cdot 18=72 \mathrm{~g}$ $\mathrm{mol}^{-1}$ ) due to the anion volume (Figure $2 \mathrm{~b}$ ).

For dynamic polymers, $\Delta q / \Delta E(\omega)$ has a similar response to the one observed for rigid polymers. However, electrogravimetric responses, during the same anion transfer, should depend on the change of film thickness associated to the conformational changes and the number of $\mathrm{H}_{2} \mathrm{O}$ transferred out of exclusion effect (Figure 3). A general theoretical expression for $\Delta m / \Delta E(\omega)$ considering both free water transfers from pure anion exclusion and free water transfer from induced conformational movements can be expressed as:

$$
\begin{array}{r}
\frac{\Delta m}{\Delta E}(\omega)=S\left(\delta_{\mathrm{A}^{-}} M_{\mathrm{A}^{-}}+n \delta_{\mathrm{H}_{2} \mathrm{O}} M_{\mathrm{H}_{2} \mathrm{O}}\right)\left[\frac{G_{\mathrm{A}^{-}}}{j \omega+K_{\mathrm{A}^{-}}^{\prime}}\right] \\
+S\left(n^{\prime} \delta_{\mathrm{H}_{2} \mathrm{O}^{\prime}}^{\prime} M_{\mathrm{H}_{2} \mathrm{O}}\right)\left[\frac{G_{\mathrm{H}_{2} \mathrm{O}^{\prime}}}{j \omega+K_{\mathrm{H}_{2} \mathrm{O}^{\prime}}^{\prime}}\right]
\end{array}
$$

where $\delta_{\mathrm{H}_{2} \mathrm{O}^{\prime}}^{\prime}$ indicates the direction of transfer and the number of molecules of $\mathrm{H}_{2} \mathrm{O}$ associated with conformational movements $\left(n^{\prime}\right)$ can be equal or different than $n . G_{\mathrm{H}_{2} \mathrm{O}^{\prime}}$ and $K_{\mathrm{H}_{2} \mathrm{O}^{\prime}}^{\prime}$ are kinetic parameters of free water transfer from induced structural movements. The method of elimination of the pure anion exclusion from electrogravimetric results to consider the contribution of other free water transfers is close to the method used by Bruckenstein and Hillman as a diagnostic for species interference[5,12,13].

In the situation (a) in Figure 3, the pure exclusion effect can be enhanced due to the contraction of film $\left(-\Delta d_{f}\right)$ during the insertion of anions, so, $\delta_{\mathrm{H}_{2} \mathrm{O}^{\prime}}^{\prime}=\delta_{\mathrm{H}_{2} \mathrm{O}}=-1$. The response leads to a net loss of mass during the oxidation of polymer (loop in the third quadrant of Figure 4)[46]. In the situation (b) of Figure 3, the pure exclusion effect is balanced due to the expansion of film thickness $\left(+\Delta d_{f}\right)$. Therefore, $\delta_{\mathrm{H}_{2} \mathrm{O}^{\prime}}^{\prime}=\delta_{\mathrm{H}_{2} \mathrm{O}}=0$, $n=n^{\prime}=0$ and the electrogravimetric response correspond to a pure anion transfer (loop in the first quadrant of Figure 4). Finally, a large expansion of film thickness $\left(+2 \Delta d_{f}\right)$ 
creates holes occupied by free $\mathrm{H}_{2} \mathrm{O}$ from solution as situation (c) of Figure 3 shows. Here, $\delta_{\mathrm{H}_{2} \mathrm{O}}=0, n=0$ and the electrogravimetric response appears in the first quadrant of Figure 4. Simplistically, the electrogravimetric responses of three situations consider similar kinetics of anion transfer and conformational changes, $G_{\mathrm{A}^{-}}=G_{\mathrm{H}_{2} \mathrm{O}^{\prime}}$ and $K_{\mathrm{A}^{-}}^{\prime}=$ $K_{\mathrm{H}_{2} \mathrm{O}^{\prime}}^{\prime}$ in eq (13). Thus, if this procedure is assumed, the kinetic constants of free water molecules experimentally obtained from $a c$-electrogravimetry, $G_{\mathrm{H}_{2} \mathrm{O}^{\prime}}$ and $K_{\mathrm{H}_{2} \mathrm{O}^{\prime}}^{\prime}$, could approximate the kinetics of conformational changes of the polymer.

\section{Experimental}

\subsection{Film preparation}

The electrochemical polymer deposition and characterization were performed by cyclic voltammetry using an AUTOLAB potentiostat-galvanostat (PGSTAT302) and a lab-made oscillator acted as an Electrochemical Quartz Crystal Microbalance at room temperature (about $295 \pm 2 \mathrm{~K}$ ). The three-electrode cell involved a reference electrode (Saturated Calomel Electrode or SCE, Tacussel XR 600) and a platinum counter electrode. The working electrode was a gold electrode $\left(S=0.3 \mathrm{~cm}^{2}\right)$ patterned on a 9 MHz quartz crystal resonator (TEMEX, France). All the solutions were prepared with deionized and double-distilled water. The potential of the working electrode is referred to the SCE reference electrode in all measurements.

POT thin films were synthetized for $a c$-electrogravimetry experiments on a gold/quartz electrode. The polymerization solution was $0.5 \mathrm{M} \mathrm{H}_{2} \mathrm{SO}_{4}$ (Fisher scientific, for trace analysis) and 0.2 M o-toluidine (Fluka). All chemicals were used as received. POT was formed through 100 voltammetric cycles between $-0.1 \mathrm{~V}$ and $0.9 \mathrm{~V}$ at $100 \mathrm{mV}$ $\mathrm{s}^{-1}$ scan rate (which equals to $\sim 40 \mu \mathrm{g} \mathrm{cm}^{-2}$ deposited film mass). The films generated following this procedure show a more open structure owing to the properties of bisulfate anions[49,50].

\subsection{Film conditioning}

POT film was 10 times cycled between $-0.1 \mathrm{~V}$ and $0.9 \mathrm{~V}$ in $0.5 \mathrm{M} \mathrm{H}_{2} \mathrm{SO}_{4}$ at 100 $\mathrm{mV} \mathrm{s}^{-1}$ until a stable cyclic voltammogram was obtained avoiding significant polymer degradation by hydrolysis[17]. Afterwards, $a c$-electrogravimetry studies were performed at steady-state potentials in the range of $0.55 \mathrm{~V}$ to $0.1 \mathrm{~V}$ in the same solution.

\section{3. $a c$-Electrogravimetry set-up}

For $a c$-electrogravimetry studies, a fast quartz crystal microbalance was coupled with a four-channel frequency response analyzer (FRA, Solartron 1254) and a potentiostat 
(SOTELEM-PGSTAT Z1). The modified working electrode was polarized at a given potential and a sinusoidal potential perturbation with a small amplitude $(10 \mathrm{mV} r m s)$ was superimposed between $65 \mathrm{kHz}$ and $0.01 \mathrm{~Hz}$. The microbalance frequency change, $\Delta f_{m}$ and the alternating current response, $\Delta I$, were sent to the four channels FRA, which allowed the electrogravimetric transfer function, $\Delta m / \Delta E(\omega)$ and the electrochemical impedance, $\Delta E / \Delta I(\omega)$, to be simultaneously obtained. Finally, the experimental data were fitted with the theoretical expressions given in Section 2 by means of LevenbergMarquardt method[51].

\section{Results and discussion}

\subsection{Kinetic model for POT films in acidic aqueous media}

In acidic solutions, the voltammetric response of POT films has two successive quasi-reversible redox process independent from the existing anion (inset of Figure 5a)[52-54]. In the oxidation direction, the first redox process involves the transfer of anions $\left(\mathrm{A}^{-}\right)$to keep the electroneutrality during the leucoemeraldine-polaron ( $\mathrm{LE} \rightleftarrows \mathrm{P}$ ) transitions. The second redox process corresponds to bipolaron-pernigraniline transitions $(\mathrm{BP} \rightleftarrows \mathrm{PN})$ with the transfer of $\mathrm{H}_{3} \mathrm{O}^{+}$which is necessary for protonation/deprotonation of electroactive sites.

By cyclic spectro-electrogravimetry and $a c$-electrogravimetry[16,53], a third reaction step was elucidated corresponding to the polaron-bipolaron $(\mathrm{P} \rightleftarrows \mathrm{BP})$ transitions with specific and independently measurable electrochemical properties. The electrochemical mechanism can be summarized as:

$$
\begin{aligned}
& \mathrm{LE}+\mathrm{A}^{-} \underset{k_{1}}{\stackrel{k_{1}^{\prime}}{\rightleftarrows}} \mathrm{P}+\mathrm{e}^{-}+x_{1} \mathrm{H}_{2} \mathrm{O} \\
& \mathrm{P}+\mathrm{A}^{-} \underset{k_{2}}{\stackrel{k_{2}^{\prime}}{\rightleftarrows}} \mathrm{BP}+\mathrm{e}^{-}+x_{2} \mathrm{H}_{2} \mathrm{O} \\
& \mathrm{BP} \underset{k_{3}^{\prime}}{\stackrel{k_{3}}{\rightleftarrows}} \mathrm{PN}+\mathrm{e}^{-}+\mathrm{H}_{3} \mathrm{O}^{+}
\end{aligned}
$$

where $x_{i}$ represents the net effective number of water molecules exchanged during the electrochemical transition and depends on the nature of the anion transferred[17]. Moreover, the electrochemical transitions of eq (14) and (15) are kinetically faster than the electrochemical transitions of eq (16).

Accordingly, $\mathrm{LE} \rightleftarrows \mathrm{P}$ (eq (14)) and $\mathrm{P} \rightleftarrows \mathrm{BP}($ eq (15)) transitions are good candidates to test the anion exclusion model for dynamic polymers. Thus, ac-electrogravimetric experiments were carried out in the potential range of $0.55 \mathrm{~V}$ to $0.1 \mathrm{~V}$ in $0.5 \mathrm{M} \mathrm{H}_{2} \mathrm{SO}_{4}$ 
acid solution. In the potential range of 0.45 and $0.1 \mathrm{~V}, \mathrm{LE} \rightleftarrows \mathrm{P}$ and $\mathrm{P} \rightleftarrows \mathrm{BP}$ transitions are expected as it was described elsewhere[53]. The experimental charge/potential transfer function results represented in a complex capacitance plane, $\Delta q / \Delta E(\omega)$, show a typical loop at $0.25 \mathrm{~V}$ associated to one charge transfer balanced by $\mathrm{HSO}_{4}^{-}$(Figure 5a). Around $0.45 \mathrm{~V}$, the partial charge transfer associated with the $\mathrm{H}_{3} \mathrm{O}^{+}$transfer must be taken into account and be separated. Moreover, the quasi-vertical branch observed at low frequencies and at potentials close to $0.1 \mathrm{~V}$ points to a slight contribution of a parasitic reaction which can be removed using a simple $R_{p}, C_{p}$ circuit.

In accordance with previous works[16], the theoretical equation of $\Delta q / \Delta E(\omega)$ for POT films in $0.5 \mathrm{M} \mathrm{H}_{2} \mathrm{SO}_{4}$ acid solution can be proposed from eq (10) considering $z_{\mathrm{HSO}_{4}^{-}}=z_{\mathrm{H}_{3} \mathrm{O}^{+}}=1$ as:

$$
\frac{\Delta q}{\Delta E}(\omega)=\frac{1}{j \omega R_{p}+\frac{1}{C_{p}}}+\frac{F G_{\mathrm{HSO}_{4}^{-}}}{(j \omega)^{\alpha_{\mathrm{HSO}_{4}^{-}}+K_{\mathrm{HSO}_{4}^{-}}^{\prime}}}+\frac{F G_{\mathrm{H}_{3} \mathrm{O}^{+}}}{(j \omega)^{\alpha_{\mathrm{H}_{3} 0^{+}}+K_{\mathrm{H}_{3} \mathrm{O}^{+}}^{\prime}}}
$$

The non-ideality of impedance spectra (deviation from a perfect semicircle) can be mathematically corrected using a constant-phase element, $(j \omega)^{\alpha}$. This fact is frequently observed in intercalation systems[55,56]. Here, $(j \omega)^{\alpha}$ is considered as a mathematical resource to achieve the best fittings and it does not cause any change in the physical meaning of the kinetic parameters[16].

Eq (17) was fitted to experimental $\Delta q / \Delta E(\omega)$ until convergence to obtain valuable kinetic information of both ions transfers. Solid line Figure 5a shows a good agreement between the experimental and simulation data using eq (17). Later, $G_{\mathrm{HSO}_{4}^{-}}$, $K_{\mathrm{HSO}_{4}^{-}}^{\prime}, \alpha_{\mathrm{HSO}_{4}^{-}}, G_{\mathrm{H}_{3} \mathrm{O}^{+}}, \quad K_{\mathrm{H}_{3} \mathrm{O}^{+}}^{\prime}$ and $\alpha_{\mathrm{H}_{3} \mathrm{O}^{+}}$parameters are used for subsequent electrogravimetric analysis. $\alpha_{\mathrm{HSO}_{4}^{-}}$and $\alpha_{\mathrm{H}_{3} \mathrm{O}^{+}}$obtained are close to the ideal system for both involved species $(0.94 \pm 0.04)$.

Figure 5b shows the corresponding electrogravimetric response of POT film at $0.25 \mathrm{~V}$. A single loop in the first quadrant indicates the increase of mass during the oxidation. Therefore, insertion of anions is expected to balance charge excess. For the multiparametric fitting process, eq (13) was used with similar modification as it is commented above in section 2. At more anodic potentials, the partial contribution to $\Delta m / \Delta E(\omega)$ associated with $\mathrm{H}_{3} \mathrm{O}^{+}$transfer was added. Finally, a general theoretical equation of $\Delta m / \Delta E(\omega)$ for POT films in $0.5 \mathrm{M} \mathrm{H}_{2} \mathrm{SO}_{4}$ acid solution considering the 
anion exclusion, free water transfer out of exclusion effect and $\mathrm{H}_{3} \mathrm{O}^{+}$transfer can be defined as:

$$
\begin{gathered}
\frac{\Delta m}{\Delta E}(\omega)=\left(\delta_{\mathrm{HSO}_{4}^{-}} M_{\mathrm{HSO}_{4}^{-}}+n \delta_{\mathrm{H}_{2} \mathrm{O}} M_{\mathrm{H}_{2} \mathrm{O}}\right)\left[\frac{G_{\mathrm{HSO}_{4}^{-}}}{(j \omega)^{\alpha \mathrm{HSO}_{4}^{-}}+K_{\mathrm{HSO}_{4}^{-}}^{\prime}}\right] \\
+\left(\delta_{\mathrm{H}_{2} \mathrm{O}^{\prime}}^{\prime} M_{\mathrm{H}_{2} \mathrm{O}}\right)\left[\frac{n^{\prime} G_{\mathrm{H}_{2} \mathrm{O}^{\prime}}}{(j \omega)^{\alpha \mathrm{H}_{2} \mathrm{O}^{\prime}}+K_{\mathrm{H}_{2} \mathrm{O}^{\prime}}^{\prime}}\right] \\
+\left(\delta_{\mathrm{H}_{3} \mathrm{O}^{+}} M_{\mathrm{H}_{3} \mathrm{O}^{+}}\right)\left[\frac{G_{\mathrm{H}_{3} \mathrm{O}^{+}}}{(j \omega)^{\alpha_{\mathrm{H}_{3} \mathrm{O}^{+}}+K_{\mathrm{H}_{3} \mathrm{O}^{+}}^{\prime}}}\right]
\end{gathered}
$$

In the present form, this function is over-parameterized. For this reason, to reduce the number of parameters, some of them were fixed. Thus, $\delta_{\mathrm{HSO}_{4}^{-}} M_{\mathrm{HSO}_{4}^{-}}$is $+97 \mathrm{~g} \mathrm{~mol}^{-1}$, $\delta_{\mathrm{H}_{2} \mathrm{O}} M_{\mathrm{H}_{2} \mathrm{O}}=-18 \mathrm{~g} \mathrm{~mol}^{-1}$ and $\delta_{\mathrm{H}_{3} \mathrm{O}^{+}} M_{\mathrm{H}_{3} \mathrm{O}^{+}}=-19 \mathrm{~g} \mathrm{~mol}^{-1}$. The parameters $G_{\mathrm{HSO}_{4}^{-}}, K_{\mathrm{HSO}_{4}^{-}}^{\prime}$, $\alpha_{\mathrm{HSO}_{4}^{-}}, G_{\mathrm{H}_{3} \mathrm{O}^{+}}, K_{\mathrm{H}_{3} \mathrm{O}^{+}}^{\prime}$ and $\alpha_{\mathrm{H}_{3} \mathrm{O}^{+}}$are fixed from results of fitted $\Delta q / \Delta E(\omega)$ function at a given polarization potential. The parameter $n$ was calculated considering $V_{\mathrm{HSO}_{4}^{-}}=47 \AA^{3}$ and $V_{\mathrm{H}_{2} \mathrm{O}}=10 \AA^{3}$ obtained from the Connolly Solvent Excluded Volume in the commercial software ChemBio3D Ultra v. 12.0 ChemBioOffice 2010, thus $n=4.7$. Initially, $\delta_{\mathrm{H}_{2} \mathrm{O}^{\prime}}^{\prime} M_{\mathrm{H}_{2} \mathrm{O}}$ could be $+18 \mathrm{~g} \mathrm{~mol}^{-1}$ or $-18 \mathrm{~g} \mathrm{~mol}^{-1}$ because the conformational changes of film are unpredictable. For this reason, both values were used to perform the fittings. The better convergence between the experimental and theoretical values were obtained using $\delta_{\mathrm{H}_{2} \mathrm{O}^{\prime}}^{\prime} M_{\mathrm{H}_{2} \mathrm{O}}=+18 \mathrm{~g} \mathrm{~mol}^{-1}$ and, for this reason, this parameter was fixed as such (solid line in Figure $5 b)$. Finally, only three parameters $\left(n^{\prime} G_{\mathrm{H}_{2} \mathrm{O}^{\prime}}, \alpha_{\mathrm{H}_{2} \mathrm{O}^{\prime}}\right.$ and $\left.K_{\mathrm{H}_{2} \mathrm{O}^{\prime}}^{\prime}\right)$ are kept free during multiparametric fittings. Like above, $\alpha_{\mathrm{H}_{2} \mathrm{O}^{\prime}}$ obtained is close to the ideality at all polarization potentials $(0.95 \pm 0.02)$.

Determination of $\boldsymbol{n}^{\prime}$. At this point, eq (17) and (18) can explain properly the electrochemical behavior of POT films, as shown by the fits obtained (solid lines in Figure 5). However, $n^{\prime}$ is still an unknown parameter and an apparent $n^{\prime} G_{\mathrm{H}_{2} \mathrm{O}^{\prime}}$ was obtained. In this form, $n^{\prime} G_{\mathrm{H}_{2} \mathrm{O}^{\prime}}$ cannot provide a valuable information on the conformational kinetics of the film but it may be refined.

As it was mentioned in section $2, n^{\prime}$ represents the number of water molecules transferred by changes of free volume inside the films owing to conformational changes during the electrochemical reactions. By taking into account the schemes provided in Figure 3, one electron transfer involves one monovalent anion transfer, the transfer of one 
set of water molecules owing to exclusion effect $\left(n \mathrm{H}_{2} \mathrm{O}\right)$ and the transfer of one set of water molecules out of exclusion effect $\left(n^{\prime} \mathrm{H}_{2} \mathrm{O}\right)$.

In terms of surface concentration, since the thickness of film is changing, the surface concentration of transferred anions would be equal to the surface concentration of transferred $n \mathrm{H}_{2} \mathrm{O}$ and transferred $n^{\prime} \mathrm{H}_{2} \mathrm{O}, \Gamma_{\mathrm{HSO}_{4}^{-}}=\Gamma_{\mathrm{H}_{2} \mathrm{O}}=\Gamma_{\mathrm{H}_{2} \mathrm{O}^{\prime}}$. Taking this into account, the stoichiometric relation between anions and $\mathrm{H}_{2} \mathrm{O}^{\prime}\left(n^{\prime}\right)$ can be estimated from the derivative of the surface insertion law with respect to the potential at $\omega=0, d \Gamma_{i} / d E$ (eq (6)) as[16,17]:

$$
\frac{n^{\prime} G_{\mathrm{H}_{2} \mathrm{O}^{\prime}}}{K_{\mathrm{H}_{2} \mathrm{O}^{\prime}}^{\prime}} \frac{K_{\mathrm{HSO}_{4}^{-}}^{\prime}}{G_{\mathrm{HSO}_{4}^{-}}}=\left.\left.n^{\prime} \frac{d \Gamma_{\mathrm{H}_{2} \mathrm{O}^{\prime}}}{d E}\right|_{\omega \rightarrow 0} \frac{d E}{d \Gamma_{\mathrm{HSO}_{4}}}\right|_{\omega \rightarrow 0}=\left.n^{\prime} \frac{d \Gamma_{\mathrm{H}_{2} \mathrm{O}^{\prime}}}{d \Gamma_{\mathrm{HSO}_{4}^{-}}}\right|_{\omega \rightarrow 0}=n^{\prime}
$$

Figure 6 shows the number of water molecules excluded per anion transfer, $n$, as a reference and the number of transferred water molecules owing to the conformational changes of film during the electrochemical reaction of POT, $n^{\prime}$, calculated from eq (19) between $0.45 \mathrm{~V}$ and $0.1 \mathrm{~V}$. As it was commented above, $n$ is a constant parameter at all polarization potentials (4.7), however, $n^{\prime}$, changes between 1 and 2 water molecules owing to the conformational changes of film with a maximum around $0.25 \mathrm{~V}$. This means that the free volume inside the film where $\mathrm{H}_{2} \mathrm{O}$ can be inserted owing to conformational changes depends on the oxidation state of film induced by the applied potential, or in other words, it depends on film structure and the amount of anions inside the film. As an example, the film is more oxidized (BP form) and anion doped at $0.45 \mathrm{~V}$ than at $0.1 \mathrm{~V}$ where POT is more reduced (LE form) and undoped of anions (Table 1).

Once $n^{\prime}$ was obtained, $G_{\mathrm{H}_{2} \mathrm{O}^{\prime}}$ can be calculated for a set of water molecules transferred during the conformational changes. Later, this parameter together with $K_{\mathrm{H}_{2} \mathrm{O}^{\prime}}^{\prime}$ will be used to evaluate the kinetics of conformational changes of POT films under the experimental conditions in this work.

Identification of electrochemical processes. Before going into the detailed analysis of the kinetic parameters, the electrochemical transitions of POT can be placed on the potential scale by means of the derivative of the surface insertion laws of $\mathrm{HSO}_{4}^{-}$, $d \Gamma_{\mathrm{HSO}_{4}^{-}}(E) / d E=G_{\mathrm{HSO}_{4}^{-}} / K_{\mathrm{HSO}_{4}^{-}}^{\prime}[16]$. The peaks in Figure 7 have the same meaning as the theoretical derivation of a voltammetric response of electrochemical processes and, in this case, they correspond to $\mathrm{LE} \rightleftarrows \mathrm{P}$ and $\mathrm{P} \rightleftarrows \mathrm{BP}$ transitions where the anion transfer takes place. The experimental result were fitted to $[16,27,57]$ : 


$$
\left.\frac{d \Gamma_{\mathrm{HSO}_{4}^{-}}}{d E}\right|_{\exp }=\left.\frac{d \Gamma_{\mathrm{HSO}_{4}^{-}}}{d E}\right|_{L E \rightleftarrows P}+\left.\frac{d \Gamma_{\mathrm{HSO}_{4}^{-}}}{d E}\right|_{P \rightleftarrows B P}
$$

where for each reaction

$$
\frac{d \Gamma_{\mathrm{HSO}_{4}^{-}}}{d E}=\frac{B_{\mathrm{HSO}_{4}^{-}}}{4} \frac{\Delta \Gamma_{\mathrm{HSO}_{4}^{-}}}{\cosh ^{2}\left[\frac{B_{\mathrm{HSO}_{4}^{-}}}{2}\left(E-E_{p, \mathrm{HSO}_{4}^{-}}\right)\right]}
$$

and $\Delta \Gamma_{\mathrm{HSO}_{4}^{-}}=\Gamma_{\mathrm{HSO}_{4}^{-}}^{\max }-\Gamma_{\mathrm{HSO}_{4}^{-}}^{\min }$ is the increment between the minimum surface concentration of the sites occupied by anions in the polymer $\left(\Gamma_{\mathrm{HSO}}^{\min }\right)$ and the maximum surface concentration of the sites available for anion insertion $\left(\Gamma_{\mathrm{HSO}_{4}}^{\max }\right)$ during the redox conversion, and $E_{p, \mathrm{HSO}_{4}^{-}}$is the peak potential where $d \Gamma(E) / d E$ is higher. Therefore, valuable information about $B_{\mathrm{HSO}_{4}^{-}}, \Delta \Gamma_{\mathrm{HSO}_{4}^{-}}$and $E_{p, \mathrm{HSO}_{4}^{-}}$can be obtained for each transition process[54].

The peak at $0.124 \mathrm{~V}$ corresponds to $\mathrm{LE} \rightleftarrows \mathrm{P}$ and the peak at $0.384 \mathrm{~V}$ to the $\mathrm{P} \rightleftarrows \mathrm{BP}$. About two $\mathrm{LE} \rightleftarrows \mathrm{P}\left(28 \mathrm{nmol} \mathrm{cm}{ }^{-2}\right)$ per one $\mathrm{P} \rightleftarrows \mathrm{BP}\left(14 \mathrm{nmol} \mathrm{cm} \mathrm{cm}^{-2}\right)$ occur in the POT film during the potential scan. This difference could be due to two possible formation of bipolaronic forms (BP) inside the film: $i$ ) electrochemically by oxidation of an electroactive site next to a formed polaron (eq (22)) or ii) by electronic reconfiguration from two electrochemically formed polarons (eq (23))[58,59]:

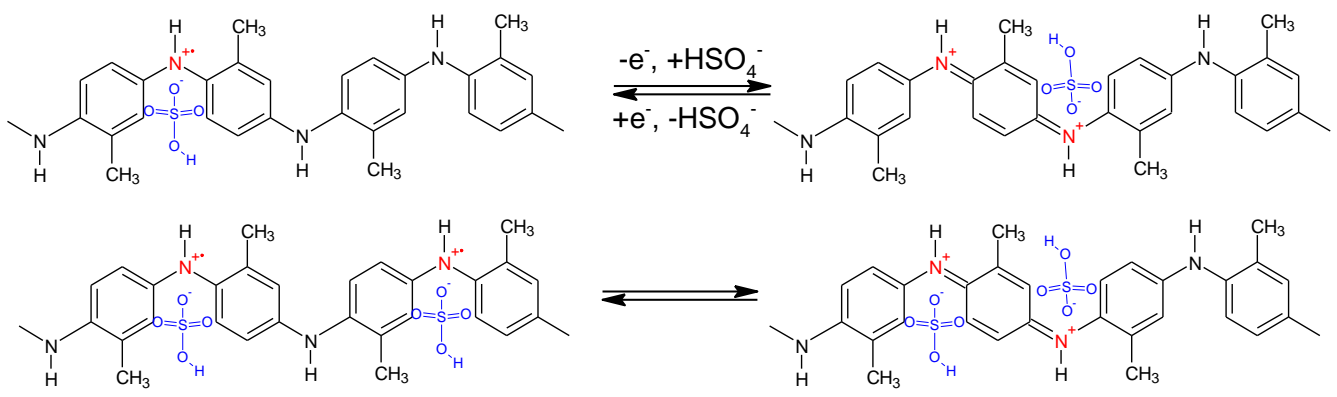

Consequently, the electronic reconfiguration in POT would reduce the amount of BP, which can be formed electrochemically by a superimposed potential.

Ease of species transfer at the polymer|solution interface. From an electrical point of view[60], kinetic parameters, $G_{i}$, are analog to the inverse of a charge transfer resistance at the polymer|solution interface, $1 / F G=R_{c t}$. Therefore, it refers to the ease of species transfer during the electrochemical reactions of electroactive films.

For anions and $\mathrm{H}_{2} \mathrm{O}^{\prime}$ transfers, two peaks of $G_{i}$ are expected because both species are involved in two different electrochemical processes, $\mathrm{LE} \rightleftarrows \mathrm{P}$ and $\mathrm{P} \rightleftarrows \mathrm{BP}$. However, anions and solvent transfers show only one peak of $G_{i}$ in Figure 8 centered at $\sim 0.32 \mathrm{~V}$ 
where both transitions take place simultaneously (see Figure 7). This particular behavior was previously explained considering that one specie (anion or water) can be inserted in two structurally different sites of the film (P or BP sites)[16].

The exponential dependence at potentials far from the peak potential agrees with the proposed model[61]:

$$
G_{i}=\frac{G_{i}^{\max }}{\cosh \left[\frac{B_{i}}{2}\left(E-E_{p, i}\right)\right]}
$$

where $i$ is $\mathrm{HSO}_{4}^{-}$or $\mathrm{H}_{2} \mathrm{O}^{\prime}, G_{i}^{\max }$ represents the maximum value for this function at $E=E_{p, i}$, and $E_{p, i}$ represent the peak potential of $G_{i}$.

By taking into account eq (5), for the direct transitions (oxidation half-reactions):

$$
\frac{B_{i}}{2}=\frac{n_{\mathrm{e}^{-}} \alpha F}{R T}
$$

and for the reverse transitions (reduction half-reactions):

$$
\frac{B_{i}}{2}=\frac{n_{\mathrm{e}^{-}}(1-\alpha) F}{R T}
$$

are obtained. Values of $\alpha=0.5$ imply that the variation of $G_{i}$ on the applied potential presents a symmetry with respect to the formal redox potential, and values for $B_{i}$ are the same for the direct and reverse transitions. In any other case, $B_{i}$ values are different, and the dependence of $G_{i}$ on the applied potential should be asymmetrical.

At $298 \mathrm{~K}, B_{i} / 2=39 \mathrm{~V}^{-1}$ for $n_{\mathrm{e}^{-}}=2$ and $\alpha=0.5$, one electron for $\mathrm{LE} \rightleftarrows \mathrm{P}$ transitions which takes place mainly between 0.1 and $0.32 \mathrm{~V}$ and one electron for $\mathrm{P} \rightleftarrows \mathrm{BP}$ transitions which takes place mainly between $0.35 \mathrm{~V}$ and $0.55 \mathrm{~V}$ [17]. Thus, it is possible to obtain an estimation of this parameter for the reverse and forward reactions from the slope of $\log \left(G_{\mathrm{H}_{2} \mathrm{O}^{\prime}}\right)$ versus $E$ plot (Figure 8).

Values obtained for the different slopes are close to $39 \mathrm{~V}^{-1}$ for $\mathrm{HSO}_{4}^{-}$and $\mathrm{H}_{2} \mathrm{O}^{\prime}$ as expected theoretically. Therefore, about $20 \mathrm{~V}^{-1}$ correspond to each of the transitions. These results are in agreement with the $\mathrm{BHSO}_{4}^{-}$values obtained from fittings of $d \Gamma_{\mathrm{HSO}_{4}^{-}}(E) / d E$ in Figure 7 where $B_{\mathrm{HSO}_{4}^{-}}$for $\mathrm{LE} \rightleftarrows \mathrm{P}$ is $13 \mathrm{~V}^{-1}$ and $B_{\mathrm{HSO}_{4}^{-}}$for $\mathrm{P} \rightleftarrows \mathrm{BP}$ is $18 \mathrm{~V}^{-}$ 1.

Previous studies of POT films immersed in different acids show relatively lower values as the anion interacts more strongly with films[17]. Lateral interactions between randomly distributed electroactive sites during the electrochemical reaction of films reduce the theoretical value of $B_{i}$ considering the Laviron model deduced from 
thermodynamic basis of the Frumkin-type isotherm[62]. Therefore, lateral interactions are more likely to occur during $\mathrm{LE} \rightleftarrows \mathrm{P}$ than during $\mathrm{P} \rightleftarrows \mathrm{BP}$. This fact can be due to the extent of doping in the film, see Table 1. Higher amount of anions inside the film (as it occurs during $\mathrm{P} \rightleftarrows \mathrm{BP}$ ) can separate the molecular chains by repulsion, as a result reduces the strength of lateral interactions. On the contrary, stronger lateral interaction can be expected at lower doped states of polymer as at potentials where LE $\rightleftarrows \mathrm{P}$ takes place, reducing the distance between charged electroactive sites (inter-chain or intra-chain).

The evolution of $G_{\mathrm{HSO}_{4}^{-}}$and $G_{\mathrm{H}_{2} \mathrm{O}^{\prime}}$ with respect to the potential is very similar; therefore, they show a similar ease to cross the polymer|solution interface. This fact agrees with the proposed model, which assumes that non-charged species transfer can be kinetically controlled by charge injection in polymeric backbone to induce conformational changes. At $0.32 \mathrm{~V}$, the formation of the polaronic structure of POT films which twists the structure (coil structures owing to the anion-POT interactions) results in more water molecules that are able to be ejected from the film owing to conformational changes $\left(n^{\prime}\right.$ close to 2 in Figure 6)[63,64]. Indirectly, this agrees with the expansion/contraction of film owing to the single/double bond transitions and to the accommodation of anions inside the film.

Rate of species transfer at the polymer|solution interface. In general, the most important feature is that all transfer processes could be kinetically controlled by injected charge in the polymer, in other words, it can be modulated depending on the applied potential. Figure 9 shows $K_{\mathrm{H}_{2} \mathrm{O}^{\prime}}^{\prime}$ and $K_{\mathrm{A}^{-}}^{\prime}$ values obtained by fittings. Although similar rates are reached for both species, interestingly some differences were found completing mechanistic details of POT electrochemistry. Between 0.1 and $0.3 \mathrm{~V}$ where mainly LE $\rightleftarrows \mathrm{P}$ takes place, the conformational changes of film allows a set of water molecules to be transferred faster than anions. The lower amount of anions inside the films could be the cause for this. On the contrary, the exclusion effect caused by anions is faster than the conformational changes when POT film is doped with anions. This takes place between 0.3 and $0.45 \mathrm{~V}$ where mainly $\mathrm{P} \rightleftarrows \mathrm{BP}$ occurs.

The maximum of transfer rate takes place in both species around $0.32 \mathrm{~V}$, as it is the case in Figure 8. As above, the creation of polaronic forms is a serious structural perturbation which can involve conformational movements of the molecular chains making the non-charged species transfer faster[63,64]. 


\section{CONCLUSIONS}

$a c$-Electrogravimetry has been used to explore the mechanistic aspects of electroactive POT thin films. A new electrogravimetric model is proposed which takes into account the exclusion of free water molecules by anions. Any other electrogravimetric response of the films can be related to the free water transfer owing to conformational movements of electroactive and dynamic film. Consequently, the kinetic aspects studied by $a c$-electrogravimetry of this kind of free water molecules act as a "fingerprint" of the kinetic aspects of polymeric movements. Here, the experimentally accessible timescale allows temporal resolution of coupled electron/anion transfer/free solvent transfer and coupled free solvent transfer/polymer structural reconfiguration.

This model was applied to an intensively studied polymer with anion dopingdedoping with interesting results, specifically to POT. The experimentally accessible timescale allows temporal resolution of species transfer and polymer reconfigurations to be determined. For this film, the kinetics of conformational changes depends on the electrochemical reaction. Slightly faster free water transfers/conformational than anion insertion is observed during $\mathrm{LE} \rightleftarrows \mathrm{P}$ transitions. On the contrary, faster anion exclusion takes place during $\mathrm{P} \rightleftarrows \mathrm{BP}$ transitions. This fact has been related to the doped state of polymer and lateral interactions between electroactive sites. A more open structure of POT allows faster anion transfers than that in the case caused by the molecular rearrangements during $\mathrm{P} \rightleftarrows \mathrm{BP}$ transitions. This fact is due to the high doping levels in POT, which reduces the strength of lateral interactions. However, faster macromolecular movements are necessary before anion transfer owing to the packed state of POT during LE $\rightleftarrows \mathrm{P}$ transitions. The packed state of POT is driven by a lower doping level involving stronger interactions.

Although this work focuses on p-type ICPs, the proposed model provides a platform to extend the mechanistic interpretation of any type of ICPs by impedance techniques where solvent transfer and polymer reconfigurations follow the charge transfer steps. Using this model, they can be temporally separated, to the best of our knowledge, in an unprecedented detail. Therefore, it suggests that there is a considerable volume of under-exploited materials and experimental conditions further available for this kind of a study. 


\section{ACKNOWLEDGMENTS}

Part of this work was supported by FEDER-CICyT project CTQ201128973/BQU.

\section{REFERENCES}

[1] L.S. Van Dyke, C.R. Martin, Electrochemical investigations of electronically conductive polymers. 4 . Controlling the supermolecular structure allows charge transport rates to be enhanced, Langmuir. 6 (1990) 1118-1123.

[2] J. Heinze, B.A. Frontana-Uribe, S. Ludwigs, Electrochemistry of Conducting Polymers-Persistent Models and New Concepts, Chem. Rev. 110 (2010) 47244771.

[3] P. Novak, K. Muller, K.S.V. Santhanam, O. Haas, Electrochemically active polymers for rechargeable batteries, Chem. Rev. 97 (1997) 207-281.

[4] A.B. Kaiser, Electronic transport properties of conducting polymers and carbon nanotubes, Rep. Prog. Phys. 64 (2001) 1-49.

[5] S. Bruckenstein, A. Hillman, Consequences of Thermodynamic Restraints on Solvent and Ion Transfer During Redox Switching of Electroactive Polymers, J. Phys. Chem. 92 (1988) 4837-4839.

[6] A.R. Hillman, N.A. Hughes, S. Bruckenstein, Dynamic separation of mobile species transfer processes at polymer modified electrodes using the electrochemical quartz crystal microbalance, Analyst. 119 (1994) 167-173.

[7] M.J. Brown, A.R. Hillman, S.J. Martin, R.W. Cernosek, H.L. Bandey, Manipulation of electroactive polymer film viscoelasticity: the roles of applied potential and frequency, J. Mater. Chem. 10 (2000) 115-126.

[8] A.R. Hillman, L. Bailey, A. Glidle, J.M. Cooper, N. Gadegaard, J.R.P. Webster, Spatial distributions of polymer and mobile species in poly(o-toluidine) films, J. Electroanal. Chem. 532 (2002) 269-276.

[9] A.R. Hillman, S.J. Daisley, S. Bruckenstein, Solvent effects on the electrochemical p-doping of PEDOT, Phys. Chem. Chem. Phys. 9 (2007) 23792388.

[10] S. Bruckenstein, J. Chen, I. Jureviciute, A.R. Hillman, Ion and solvent transfers accompanying redox switching of polypyrrole films immersed in divalent anion solutions, Electrochimica Acta. 54 (2009) 3516-3525.

[11] T.F. Otero, J.G. Martinez, Artificial Muscles: A Tool To Quantify Exchanged Solvent during Biomimetic Reactions, Chem. Mater. 24 (2012) 4093-4099.

[12] A. Hillman, D. Loveday, M. Swann, S. Bruckenstein, C. Wilde, Transport of Neutral Species in Electroactive Polymer-Films, J. Chem. Soc.-Faraday Trans. 87 (1991) 2047-2053.

[13] S. Bruckenstein, A. Hillman, Solvent and Salt Transfer Upon Redox Switching of Electroactive Polymers, J. Phys. Chem. 95 (1991) 10748-10752.

[14] A.R. Hillman, M.A. Mohamoud, Ion, solvent and polymer dynamics in polyaniline conducting polymer films, Electrochimica Acta. 51 (2006) 6018-6024.

[15] A.R. Hillman, M.A. Mohamoud, S. Bruckenstein, Modelling mobile species dynamics within electroactive films under mixed thermodynamic and kinetic control, Electroanalysis. 17 (2005) 1421-1432.

[16] J. Agrisuelas, C. Gabrielli, J.J. García-Jareño, H. Perrot, F. Vicente, Kinetic and Mechanistic Aspects of a Poly(o-Toluidine)-Modified Gold Electrode. 2. Alternating Current Electrogravimetry Study in H2SO4 Solutions, J. Phys. Chem. C. 116 (2012) 15630-15640. 
[17] J. Agrisuelas, C. Gabrielli, J.J. García-Jareño, H. Perrot, F. Vicente, Effects of anion size on the electrochemical behavior of $\mathrm{H} 2 \mathrm{SO} 4$-structured poly(o-toluidine) films. An ac-electrogravimetry study in acid solutions, Electrochimica Acta. 132 (2014) 561-573.

[18] M. Vilas-Boas, M.J. Henderson, C. Freire, A.R. Hillman, E. Vieil, A combined electrochemical quartz-crystal microbalance probe beam deflection (EQCM-PBD) study of solvent and ion transfers at a poly[Ni(saltMe)]-modified electrode during redox switching, Chem.- Eur. J. 6 (2000) 1160-1167.

[19] A.R. Hillman, S.J. Daisley, S. Bruckenstein, Kinetics and mechanism of the electrochemical p-doping of PEDOT, Electrochem. Commun. 9 (2007) 13161322.

[20] S. Pruneanu, E. Csahok, V. Kertesz, G. Inzelt, Electrochemical quartz crystal microbalance study of the influence of the solution composition on the behaviour of poly(aniline) electrodes, Electrochimica Acta. 43 (1998) 2305-2323.

[21] G. Inzelt, Simultaneous chronoamperometric and quartz crystal microbalance studies of redox transformations of polyaniline films, Electrochimica Acta. 45 (2000) 3865-3876.

[22] C. Gabrielli, H. Perrot, A. Rubin, M.C. Pham, B. Piro, Ac-electrogravimetry study of ionic exchanges on a polypyrrole modified electrode in various electrolytes, Electrochem. Commun. 9 (2007) 2196-2201.

[23] A. Rubin, H. Perrot, C. Gabrielli, M.C. Pham, B. Piro, Electrochemical and electrogravimetric behaviors of conducting polymer. Theoretical aspects and application to co-polymer films based on juglone, Electrochimica Acta. 55 (2010) 6136-6146.

[24] L.T.T. Kim, O. Sel, C. Debiemme-Chouvy, C. Gabrielli, C. Laberty-Robert, H. Perrot, C. Sanchez, Proton transport properties in hybrid membranes investigated by ac-electrogravimetry, Electrochem. Commun. 12 (2010) 1136-1139.

[25] J. Agrisuelas, C. Gabrielli, J.J. Garcia-Jareño, H. Perrot, F. Vicente, Ionic and Free Solvent Motion in Poly(azure A) Studied by ac-Electrogravimetry, J. Phys. Chem. C. 115 (2011) 11132-11139.

[26] J. Agrisuelas, J.J. Garcia-Jareño, F. Vicente, Identification of Processes Associated with Different Iron Sites in the Prussian Blue Structure by in Situ Electrochemical, Gravimetric, and Spectroscopic Techniques in the dc and ac Regimes, J. Phys. Chem. C. 116 (2012) 1935-1947.

[27] C. Gabrielli, M. Keddam, N. Nadi, H. Perrot, Ions and solvent transport across conducting polymers investigated by ac electrogravimetry. Application to polyaniline, J. Electroanal. Chem. 485 (2000) 101-113.

[28] C. Gabrielli, J.J. Garcia-Jareño, H. Perrot, Charge compensation process in polypyrrole studied by ac electrogravimetry, Electrochimica Acta. 46 (2001) 4095-4103.

[29] A. Bund, S. Neudeck, Effect of the solvent and the anion on the doping/dedoping behavior of poly(3,4-ethylenedioxythiophene) films studied with the electrochemical quartz microbalance, J. Phys. Chem. B. 108 (2004) 17845-17850.

[30] W. Plieth, A. Bund, U. Rammelt, S. Neudeck, L.M. Duc, The role of ion and solvent transport during the redox process of conducting polymers, Electrochimica Acta. 51 (2006) 2366-2372.

[31] T.F. Otero, J.G. Martinez, Biomimetic intracellular matrix (ICM) materials, properties and functions. Full integration of actuators and sensors, J. Mater. Chem. B. 1 (2013) 26-38. 
[32] T.F. Otero, J.G. Martinez, Structural and Biomimetic Chemical Kinetics: Kinetic Magnitudes Include Structural Information, Adv. Funct. Mater. 23 (2013) 404416.

[33] K. Kaneto, M. Kaneko, Contribution of conformational change of polymer structure to electrochemomechanical deformation based on polyaniline, Appl. Biochem. Biotechnol. 96 (2001) 13-23.

[34] L. Lizarraga, E.M. Andrade, M.I. Florit, F.V. Molina, Quasi-Equilibrium Volume Changes of Polyaniline Films upon Redox Switching. Formal Potential Distribution and Configurational Modeling, J. Phys. Chem. B. 109 (2005) 1881518821.

[35] L.T.T. Kim, C. Gabrielli, A. Pailleret, H. Perrot, Correlation between ionexchange properties and swelling/shrinking processes in hexasulfonated calix[6]arene doped polypyrrole films: ac-electrogravimetry and electrochemical atomic force microscopy investigations, Electrochimica Acta. 56 (2011) 35163525 .

[36] Y. Lee, C. Chang, S. Yau, L. Fan, Y. Yang, L.O. Yang, K. Itaya, Conformations of Polyaniline Molecules Adsorbed on Au(111) Probed by in Situ STM and ex Situ XPS and NEXAFS, J. Am. Chem. Soc. 131 (2009) 6468-6474.

[37] M. Jozefowicz, A. Epstein, J. Pouget, J. Masters, A. Ray, A. Macdiarmid, X-Ray Structure of the Polyaniline Derivative Poly(ortho-Toluidine) - the Structural Origin of Charge Localization, Macromolecules. 24 (1991) 5863-5866.

[38] D. Kumar, Poly(o-toluidine) polymer as electrochromic material, Eur. Polym. J. 37 (2001) 1721-1725.

[39] J.-B. Raoof, R. Ojani, S.R. Hosseini, A novel, effective and low cost catalyst for methanol oxidation based on nickel ions dispersed onto poly(o-toluidine)/Triton X-100 film at the surface of multi-walled carbon nanotube paste electrode, J. Power Sources. 196 (2011) 1855-1863.

[40] D.D. Borole, U.R. Kapadi, P.P. Mahulikar, D.G. Hundiwale, Glucose oxidase electrodes of poly(o-anisidine), poly(o-toluidine), and their copolymer as biosensors: A comparative study, J. Appl. Polym. Sci. 94 (2004) 1877-1884.

[41] A. Hillman, D. Loveday, M. Swann, S. Bruckenstein, C. Wilde, Mobile Species Uptake by Polymer-Modified Electrodes, Analyst. 117 (1992) 1251-1257.

[42] C. Gabrielli, J.J. García-Jareño, M. Keddam, H. Perrot, F. Vicente, AcElectrogravimetry Study of Electroactive Thin Films. I. Application to Prussian Blue, J. Phys. Chem. B. 106 (2002) 3182-3191.

[43] C. Gabrielli, J.J. Garcia-Jareño, M. Keddam, H. Perrot, F. Vicente, AcElectrogravimetry Study of Electroactive Thin Films. II. Application to Polypyrrole, J. Phys. Chem. B. 106 (2002) 3192-3201.

[44] C. Gabrielli, M. Keddam, N. Nadi, H. Perrot, ac Electrogravimetry on conducting polymers. Application to polyaniline, Electrochimica Acta. 44 (1999) 2095-2103.

[45] C. Gabrielli, J. Garcia-Jareño, H. Perrot, Charge transport in electroactive thin films investigated by ac electrogravimetry, ACH-Models Chem. 137 (2000) 269297.

[46] J. Agrisuelas, J.J. Garcia-Jareño, D. Gimenez-Romero, F. Vicente, Innovative Combination of Three Alternating Current Relaxation Techniques: Electrical Charge, Mass, and Color Impedance Spectroscopy. Part I: The Tool, J. Phys. Chem. C. 113 (2009) 8430-8437.

[47] J. Agrisuelas, J. Juan Garcia-Jareño, D. Gimenez-Romero, F. Vicente, Innovative Combination of Three Alternating Current Relaxation Techniques: Electrical 
Charge, Mass, and Color Impedance Spectroscopy. Part II: Prussian Blue reversible arrow Everitt's Salt Process, J. Phys. Chem. C. 113 (2009) 8438-8446.

[48] L.T.T. Kim, C. Gabrielli, A. Pailleret, H. Perrot, Ions/Solvent Exchanges and Electromechanical Processes in Hexasulfonated Calix[6]Arene Doped Polypyrrole Films: Towards a Relaxation Mechanism, Electrochem. Solid State Lett. 14 (2011) F9-F11.

[49] G. Zotti, S. Cattarin, N. Comisso, Cyclic Potential Sweep Electropolymerization of Aniline - the Role of Anions in the Polymerization Mechanism, J. Electroanal. Chem. 239 (1988) 387-396.

[50] A. Elmansouri, A. Outzourhit, A. Lachkar, N. Hadik, A. Abouelaoualim, M.E. Achour, A. Oueriagli, E.L. Ameziane, Influence of the counter ion on the properties of poly(o-toluidine) thin films and their Schottky diodes, Synth. Met. 159 (2009) 292-297.

[51] J.R. Macdonald, Comparison and application of two methods for the least squares analysis of immittance data, Solid State Ion. 58 (1992) 97-107.

[52] M.J. Henderson, A.R. Hillman, E. Vieil, Chronoamperometric resolution of ion and solvent transfers at a poly(o-toluidine) modified electrode by combined electrochemical quartz crystal microbalance (EQCM) and probe beam deflection (PBD), Electrochimica Acta. 45 (2000) 3885-3894.

[53] J. Agrisuelas, C. Gabrielli, J.J. García-Jareño, H. Perrot, F. Vicente, Kinetic and Mechanistic Aspects of a Poly(o-toluidine)-Modified Gold Electrode. 1. Simultaneous Cyclic Spectroelectrochemistry and Electrogravimetry Studies in H2SO4 Solutions, J. Phys. Chem. C. 116 (2012) 15620-15629.

[54] J. Agrisuelas, C. Gabrielli, J.J. Garcia-Jareño, H. Perrot, F. Vicente, Effects of anions size on the redox behavior of poly(o-toluidine) in acid solutions. An in situ vis-NIR cyclic spectroelectrogravimetry study, Electrochimica Acta. 125 (2014) 83-93.

[55] C. Gabrielli, H. Takenouti, O. Haas, A. Tsukada, Impedance Investigation of the Charge Transport in Film-Modified Electrodes, J. Electroanal. Chem. 302 (1991) 59-89.

[56] M. Mathias, O. Haas, An Alternating-Current Impedance Model Including Migration and Redox-Site Interactions at Polymer-Modified Electrodes, J. Phys. Chem. 96 (1992) 3174-3182.

[57] J. Agrisuelas, J.J. García-Jareño, D. Gimenez-Romero, F. Vicente, An approach to the electrochemical activity of poly-(phenothiazines) by complementary electrochemical impedance spectroscopy and Vis-NIR spectroscopy, Electrochimica Acta. 55 (2010) 6128-6135.

[58] E.M. Genies, M. Lapkowski, Polyaniline films. Electrochemical redox mechanisms, Synth. Met. 24 (1988) 61-68.

[59] W.J. Albery, Z. Chen, B.R. Horrocks, A.R. Mount, P.J. Wilson, D. Bloor, A.T. Monkman, C.M. Elliott, Spectroscopic and electrochemical studies of charge transfer in modified electrodes, Faraday Discuss. Chem. Soc. 88 (1989) 247-259.

[60] D. Benito, C. Gabrielli, J.J. García-Jareño, M. Keddam, H. Perrot, F. Vicente, An electrochemical impedance and ac-electrogravimetry study of PNR films in aqueous salt media, Electrochem. Commun. 4 (2002) 613-619.

[61] J. Agrisuelas, C. Gabrielli, J.J. Garcia-Jareño, D. Gimenez-Romero, J. Gregori, H. Perrot, F. Vicente, Usefulness of $\mathrm{F}(\mathrm{dm} / \mathrm{dQ})$ function for elucidating the ions role in PB films, J. Electrochem. Soc. 154 (2007) F134-F140.

[62] E. Laviron, The use of linear potential sweep voltammetry and of a.c. voltammetry for the study of the surface electrochemical reaction of strongly 
adsorbed systems and of redox modified electrodes, J. Electroanal. Chem.

Interfacial Electrochem. 100 (1979) 263-270.

[63] J.N. Petrova, J.R. Romanova, G.K. Madjarova, A.N. Ivanova, A.V. Tadjer, Fully Doped Oligomers of Emeraldine Salt: Polaronic versus Bipolaronic Configuration, J. Phys. Chem. B. 115 (2011) 3765-3776.

[64] W.S. Huang, A.G. Macdiarmid, Optical-Properties of Polyaniline, Polymer. 34 (1993) 1833-1845. 


\section{TABLES}

Table 1. Variation of the global insertion law by integration of the simulated partial curves of $d \Gamma_{\mathrm{HSO}_{4}^{-}} / d E$ of POT film in $0.5 \mathrm{M} \mathrm{H}_{2} \mathrm{SO}_{4}$ aqueous solution of Figure 7. Total $\Gamma_{\mathrm{HSO}_{4}^{-}}$and $\Gamma_{\mathrm{HSO}_{4}^{-}}$of $\mathrm{LE} \rightleftarrows \mathrm{P}$ and $\mathrm{P} \rightleftarrows \mathrm{BP}$ transitions are calculated.

\begin{tabular}{lccc}
\hline & $\mathrm{LE} \rightleftarrows \mathrm{P}$ & $\mathrm{P} \rightleftarrows \mathrm{BP}$ & Total \\
\hline$E / \mathrm{V}$ & \multicolumn{3}{c}{$\Gamma_{\mathrm{HSO}_{4}^{-}} / \mathrm{nmol} \mathrm{cm}^{-2}$} \\
\hline 0.1 & 0 & 0 & 0 \\
0.15 & 4.6 & 0.1 & 4.7 \\
0.2 & 8.7 & 0.4 & 9.1 \\
0.25 & 11.8 & 1.0 & 12.8 \\
0.3 & 13.8 & 2.4 & 16.2 \\
0.35 & 14.9 & 4.8 & 19.7 \\
0.4 & 15.6 & 7.8 & 23.4 \\
0.45 & 15.9 & 10.6 & 26.5 \\
\hline
\end{tabular}




\section{FIGURES CAPTIONS}

Figure 1. Scheme of the electrode|polymer|solution electrode during p-doping of a rigid polymer by anions $\left(\mathrm{A}^{-}\right)$considering the exclusion of free water molecules $\left(\mathrm{H}_{2} \mathrm{O}\right) . d_{f}$ is the polymer film thickness. $k_{\mathrm{A}^{-}}$and $k_{\mathrm{e}^{-}}$are the kinetic constants of anion and electron expulsion from polymer, respectively. $k_{\mathrm{A}^{-}}^{\prime}$ and $k_{\mathrm{e}^{-}}^{\prime}$ are the kinetic constants of anion and electron insertion to polymer, respectively. The circles represent the molecule volume. In this case, $V_{\mathrm{A}^{-}}=4 V_{\mathrm{H}_{2} \mathrm{O}}$. The different color of water molecules allows the water inside film and water in solution to be distinguished.

Figure 2. Simulation in the complex plane of $\Delta q / \Delta E(\omega)$ (a) and $\Delta m / \Delta E(\omega)$ (b) considering a pure exclusion of effect like in Figure 1 between $40 \mathrm{KHz}$ and $1 \mathrm{mHz}$ of frequency perturbation. The parameters used in eq (10) and (12) are $G_{\mathrm{A}^{-}}=1 \times 10^{-5} \mathrm{~mol}$ $\mathrm{cm}^{-2} \mathrm{~V}^{-1}, K_{\mathrm{A}^{-}}^{\prime}=70 \mathrm{~s}^{-1}, z_{\mathrm{A}^{-}}=1, S=0.3 \mathrm{~cm}^{2}, \delta_{\mathrm{A}^{-}} M_{\mathrm{A}^{-}}=+80 \mathrm{~g} \mathrm{~mol}^{-1}, \delta_{\mathrm{H}_{2} \mathrm{O}} M_{\mathrm{H}_{2} \mathrm{O}}=-18$ $\mathrm{g} \mathrm{mol}^{-1} . n=4$, therefore the volume of one anion exclude 4 water molecules $\left(V_{\mathrm{A}^{-}}=\right.$ $4 V_{\mathrm{H}_{2} \mathrm{O}}$ ). Black squares are global $a c$-electrogravimetric response, red circles are the partial $a c$-electrogravimetric response of anion and blue triangles are the partial $a c$ electrogravimetric response of free $\mathrm{H}_{2} \mathrm{O}$.

Figure 3. Scheme of the electrode|polymer|solution electrode during p-doping of a polymer by anions $\left(\mathrm{A}^{-}\right)$considering the contraction of polymer (a), the expansion of polymer (b) and (c) together with the transfer of water molecules. $k_{\mathrm{A}^{-}}$and $k_{\mathrm{e}^{-}}$are the kinetic constants of anion and electron expulsion from polymer, respectively. $k_{\mathrm{A}^{-}}^{\prime}$ and $k_{\mathrm{e}^{-}}^{\prime}$ are the kinetic constants of anion and electron insertion to polymer, respectively. $\Delta d_{f}$ is the film thickness increment. The different color of water molecules allows $\mathrm{H}_{2} \mathrm{O}$ from film and solution to be distinguished.

Figure 4. Simulation in the complex plane of $\Delta m / \Delta E(\omega)$ considering the exclusion of effect between $40 \mathrm{KHz}$ and $1 \mathrm{mHz}$ of frequency perturbation together with changes of polymer thickness like in Figure 3 . The parameters used in eq (13) are $G_{\mathrm{A}^{-}}=G_{\mathrm{H}_{2} \mathrm{O}^{\prime}}=$ $1 \times 10^{-5} \mathrm{~mol} \mathrm{~cm} \mathrm{~V}^{-2}, K_{\mathrm{A}^{-}}^{\prime}=K_{\mathrm{H}_{2} \mathrm{O}^{\prime}}^{\prime}=70 \mathrm{~s}^{-1}, z_{\mathrm{A}^{-}}=1, S=0.3 \mathrm{~cm}^{2}, \delta_{\mathrm{A}^{-}} M_{\mathrm{A}^{-}}=+80 \mathrm{~g} \mathrm{~mol}^{-}$ 1 and $M_{\mathrm{H}_{2} \mathrm{O}}=18 \mathrm{~g} \mathrm{~mol}^{-1}$. In situation (a), $\delta_{\mathrm{H}_{2} \mathrm{O}^{\prime}}^{\prime}=\delta_{\mathrm{H}_{2} \mathrm{O}}=-1$ and $n=n^{\prime}=4$. In 
situation $(\mathrm{b}), \delta_{\mathrm{H}_{2} \mathrm{O}^{\prime}}^{\prime}=\delta_{\mathrm{H}_{2} \mathrm{O}}=0$ and $n=n^{\prime}=0$. In situation $(\mathrm{c}), \delta_{\mathrm{H}_{2} \mathrm{O}^{\prime}}^{\prime}=1, n^{\prime}=4$, $\delta_{\mathrm{H}_{2} \mathrm{O}}=0$ and $n=0$.

Figure 5. Experimental and theoretical charge/potential transfer function, $\Delta q / \Delta E(\omega)$ (a), and mass/potential transfer function, $\Delta m / \Delta E(\omega)$ (b), of POT film in $0.5 \mathrm{M} \mathrm{H}_{2} \mathrm{SO}_{4}$ aqueous solution at $0.25 \mathrm{~V}$. Cyclic voltammetry of a POT film between $-0.1 \mathrm{~V}$ and $0.9 \mathrm{~V}$ at $100 \mathrm{mV} \mathrm{s}^{-1}$ in the same solution in the inset of (a).

Figure 6. Number of water molecules $\left(\mathrm{H}_{2} \mathrm{O}\right)$ excluded per anion transfer, $n$, and number of transferred water molecules $\left(\mathrm{H}_{2} \mathrm{O}^{\prime}\right)$ owing to conformational changes, $n^{\prime}$, calculated from eq (19) between $0.45 \mathrm{~V}$ and $0.1 \mathrm{~V}$ of POT film in $0.5 \mathrm{M} \mathrm{H}_{2} \mathrm{SO}_{4}$ aqueous solution.

Figure 7. Evolution of the derivative of the insertion law of $\mathrm{HSO}_{4}^{-}, d \Gamma_{\mathrm{HSO}_{4}^{-}} / d E$, at different polarization potentials of POT film in $0.5 \mathrm{M} \mathrm{H}_{2} \mathrm{SO}_{4}$ aqueous solution. Solid lines are simulations with eq (20) and (21) using the reached parameters by fitting of experimental results (red circles) where $\mathrm{LE} \rightleftarrows \mathrm{P}$ and $\mathrm{P} \rightleftarrows \mathrm{BP}$ transitions can be separated. The parameters are included inside the plot for each transition.

Figure 8. $G_{\mathrm{HSO}_{4}^{-}}$and $G_{\mathrm{H}_{2} \mathrm{O}^{\prime}}$ evolution with respect to potentials perturbation obtained by fitting $\Delta q / \Delta E(\omega)$ and $\Delta m / \Delta E(\omega)$ of POT film in $0.5 \mathrm{M} \mathrm{H}_{2} \mathrm{SO}_{4}$ aqueous solution.

Figure 9. Rate transfer of exclusion effect represented with values of $K_{\mathrm{HSO}_{4}^{-}}^{\prime}$ and rate transfer of conformational changes represented with the values of $K_{\mathrm{H}_{2} \mathrm{O}^{\prime}}^{\prime}$ at different polarization potentials obtained by fitting $\Delta q / \Delta E(\omega)$ and $\Delta m / \Delta E(\omega)$ with the theoretical functions of POT film in $0.5 \mathrm{M} \mathrm{H}_{2} \mathrm{SO}_{4}$ aqueous solution. 


\section{FIGURES}
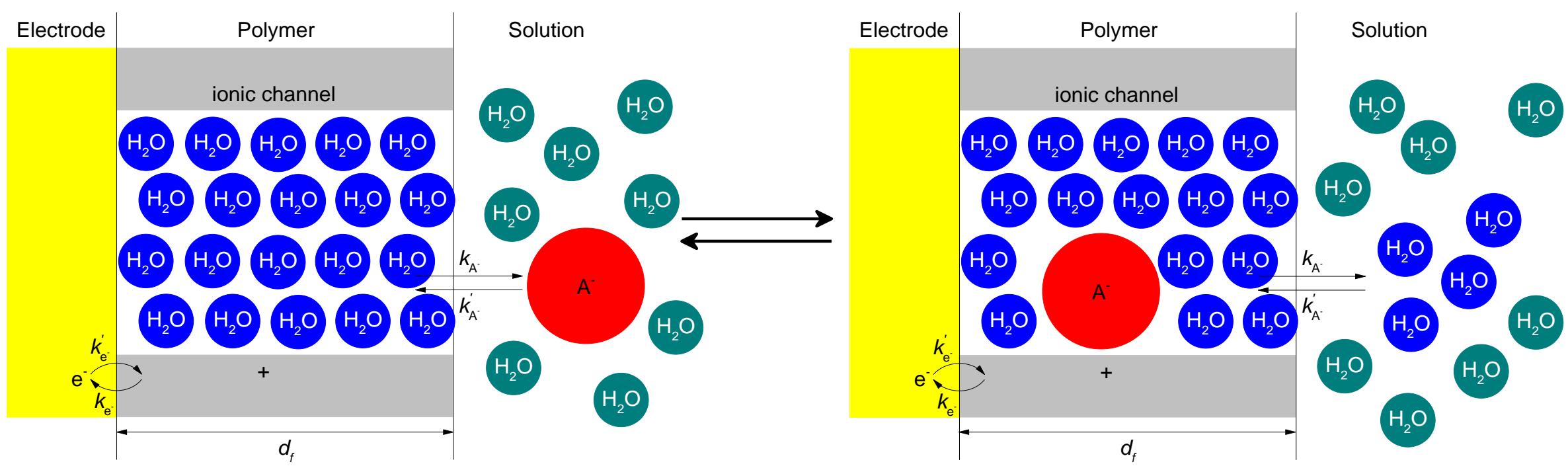

Figure 1 


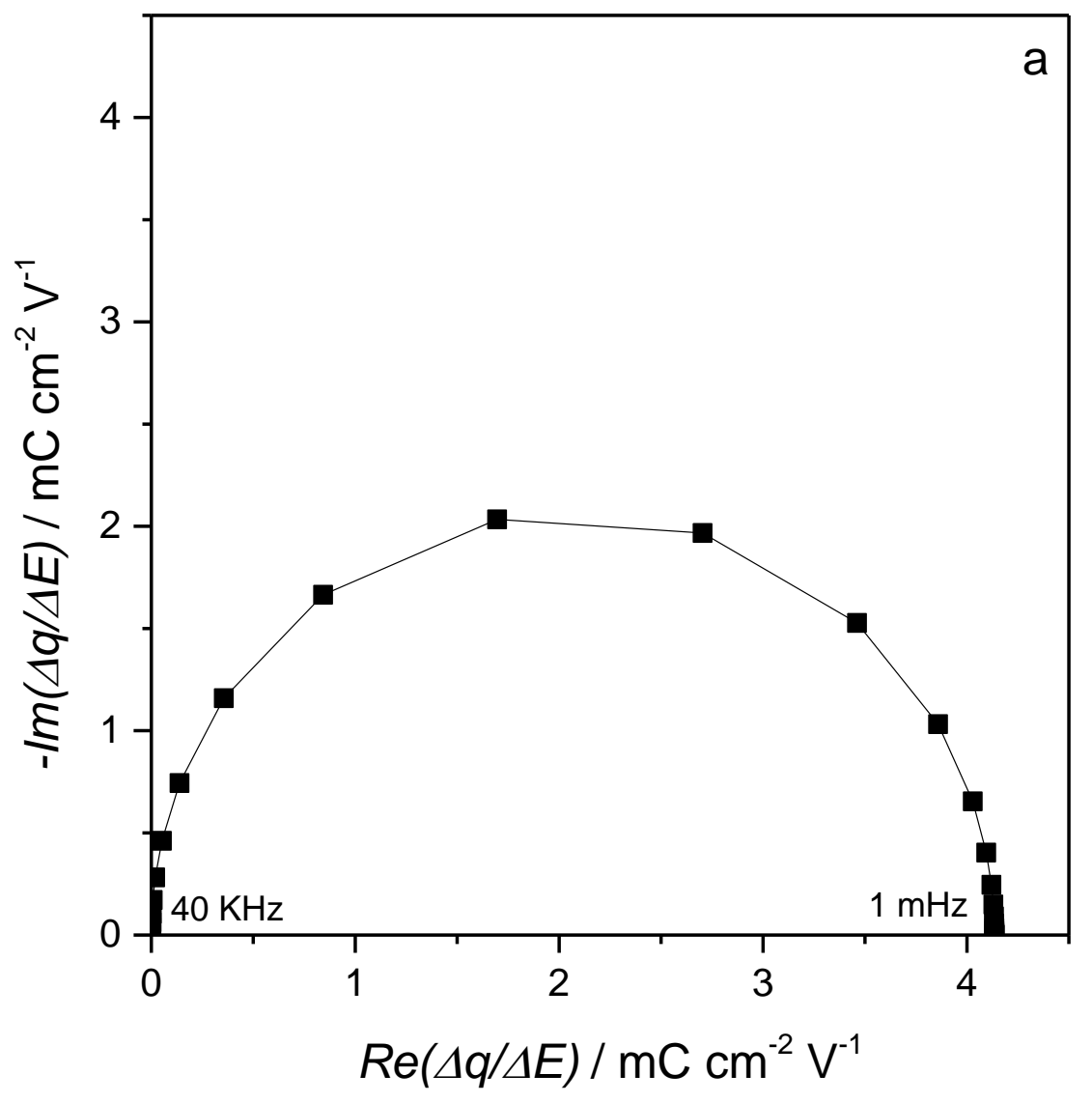

Figure 2a 


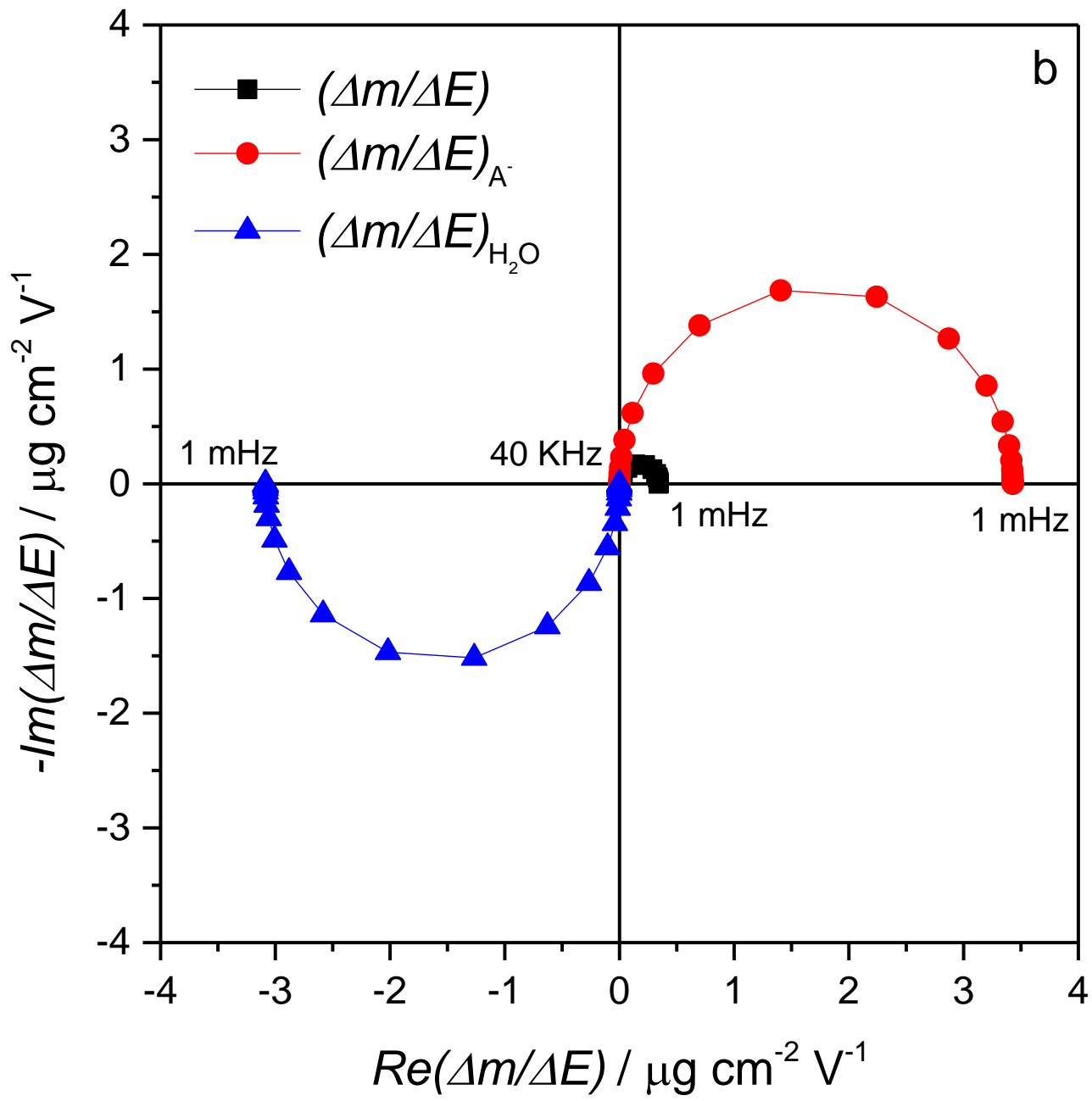

Figure $2 b$ 


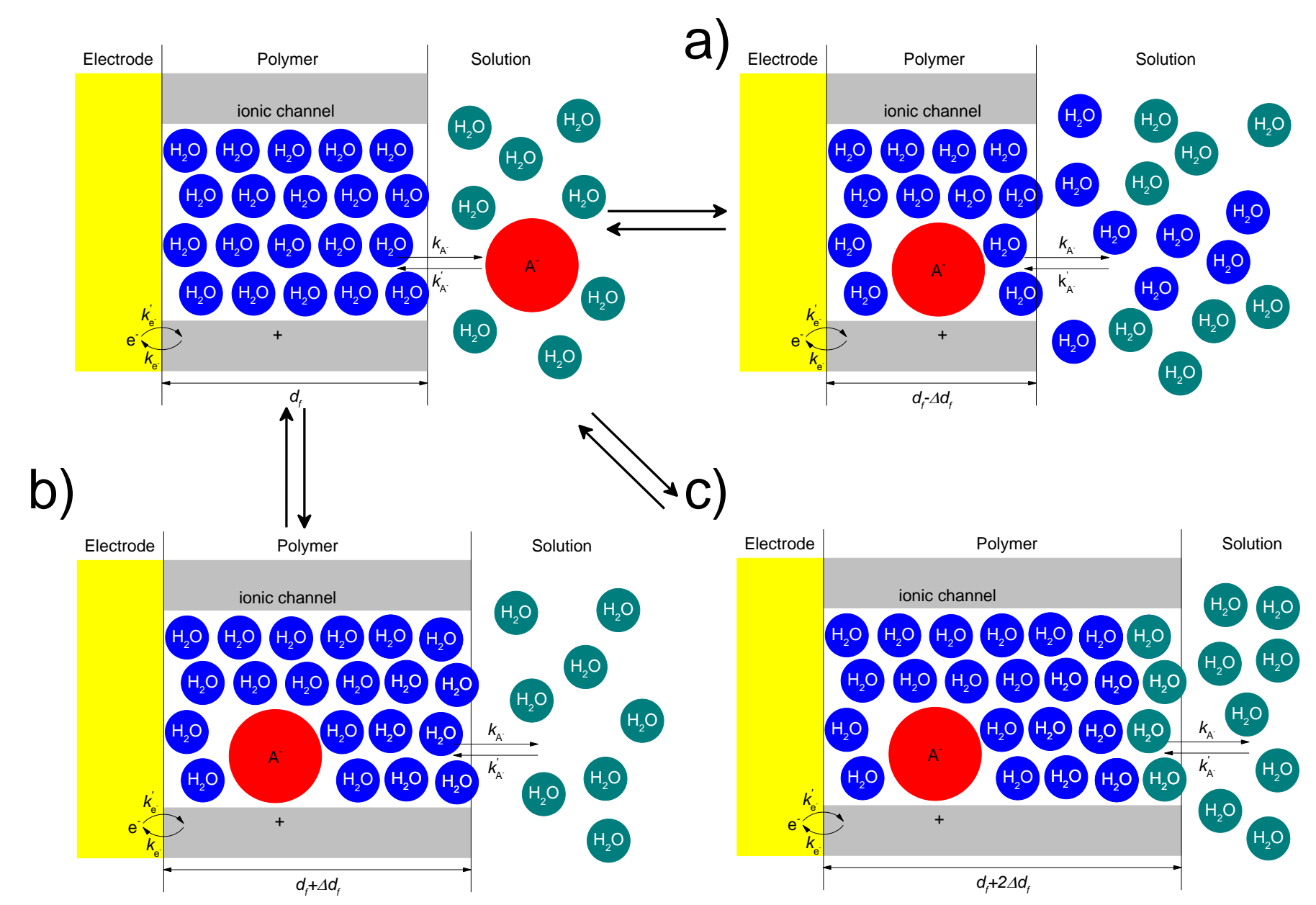

Figure 3 


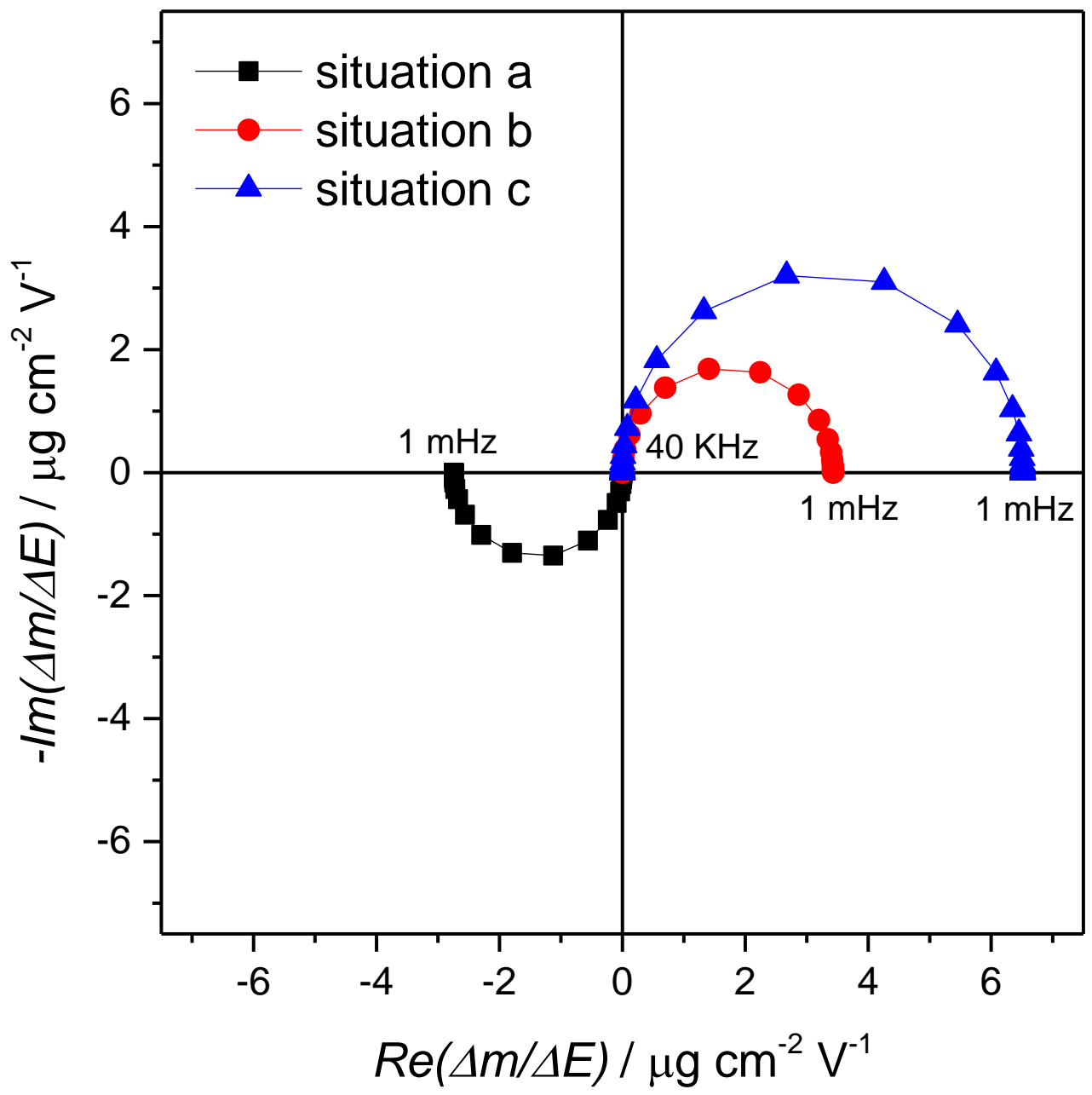

Figure 4 


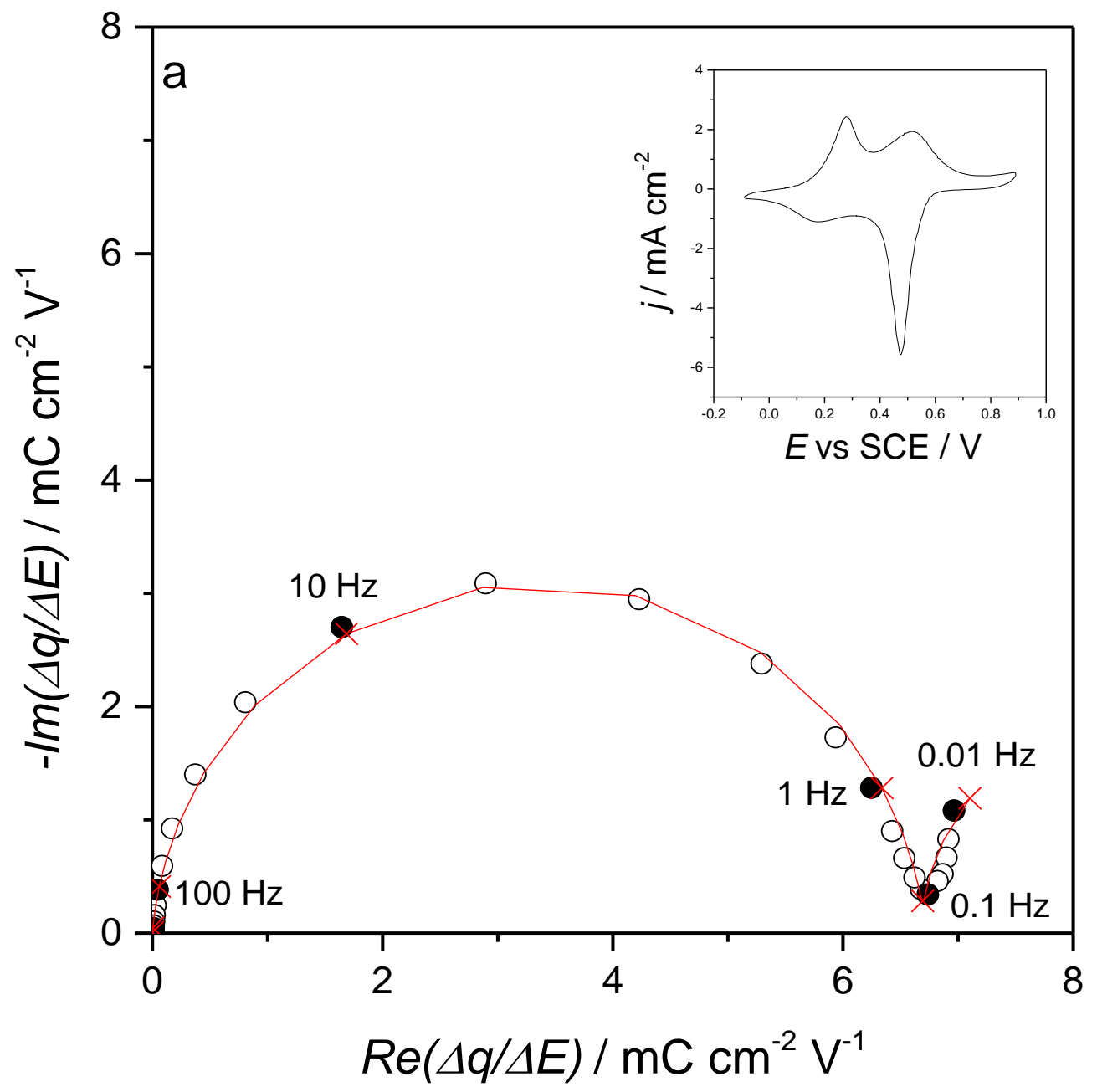

Figure 5a 


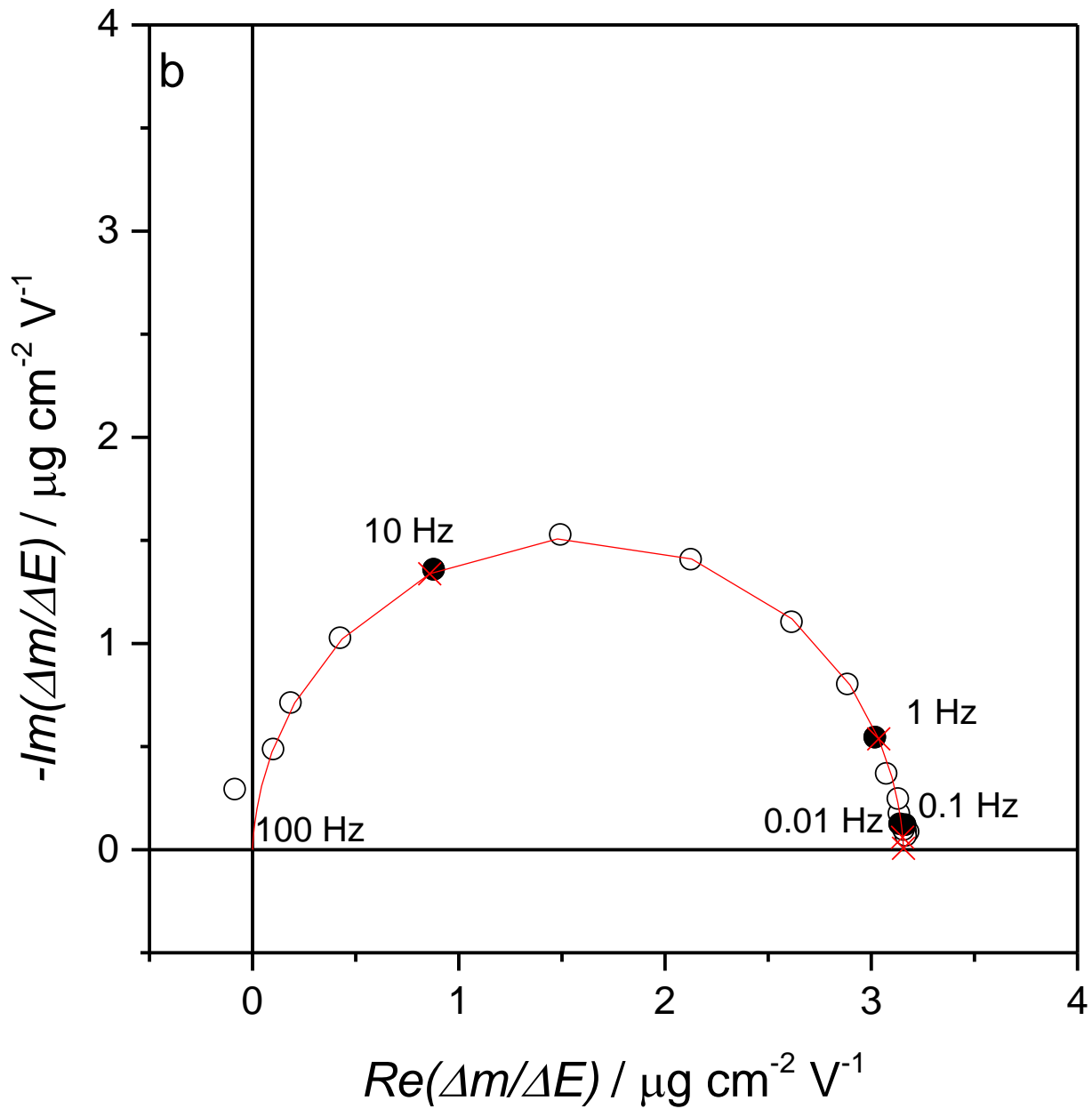

Figure $5 b$ 


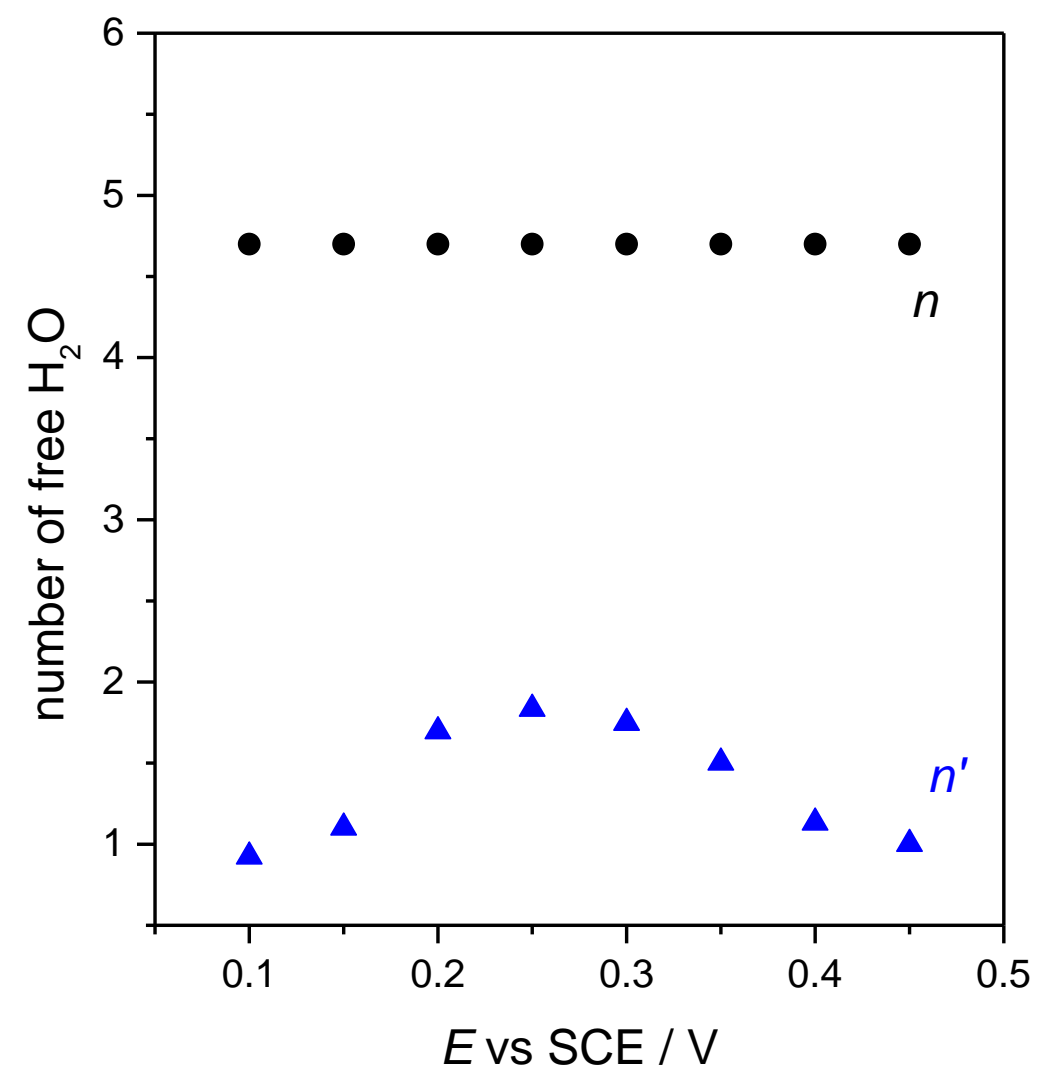

Figure 6 


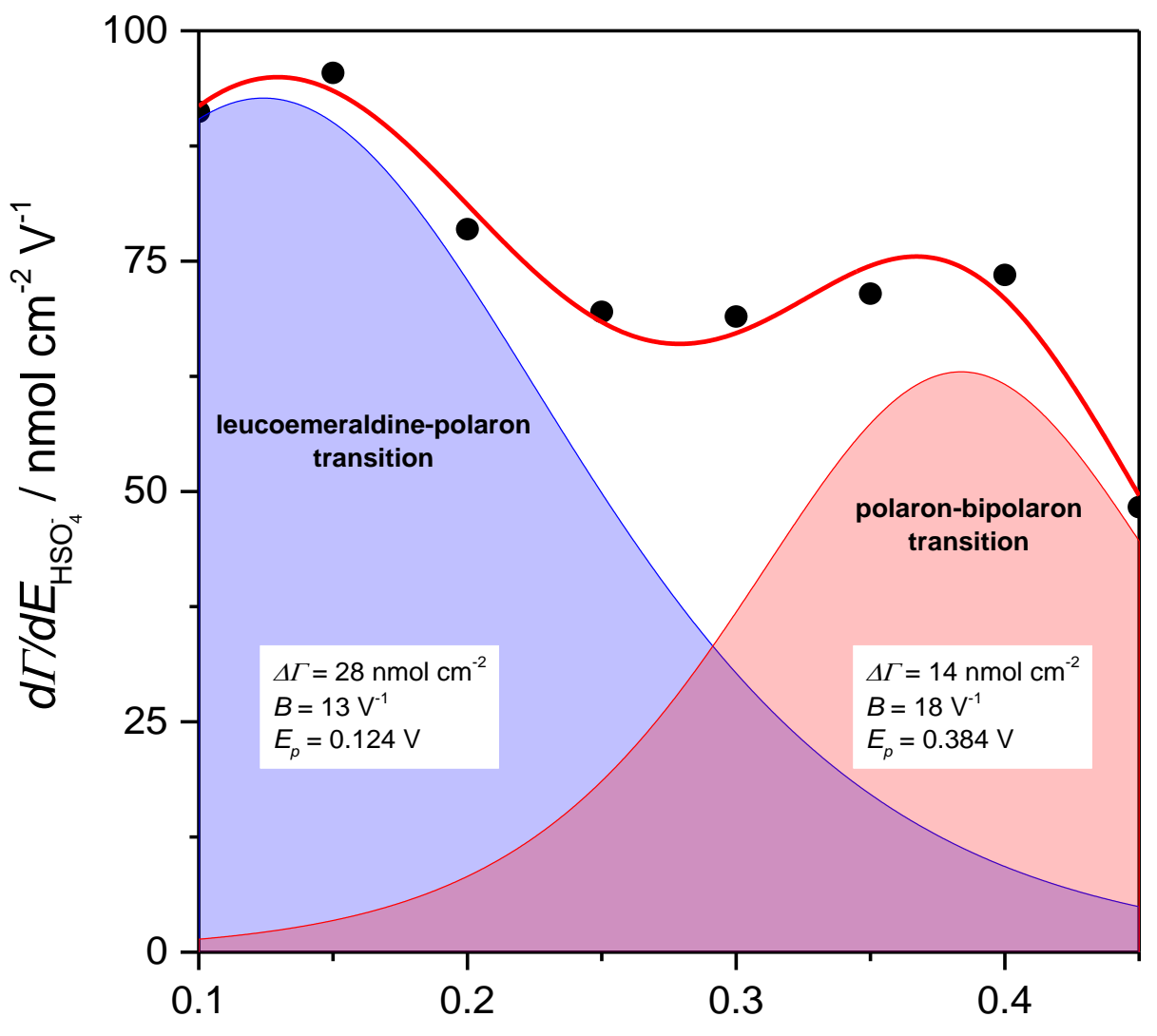

Evs SCE / V

Figure 7 


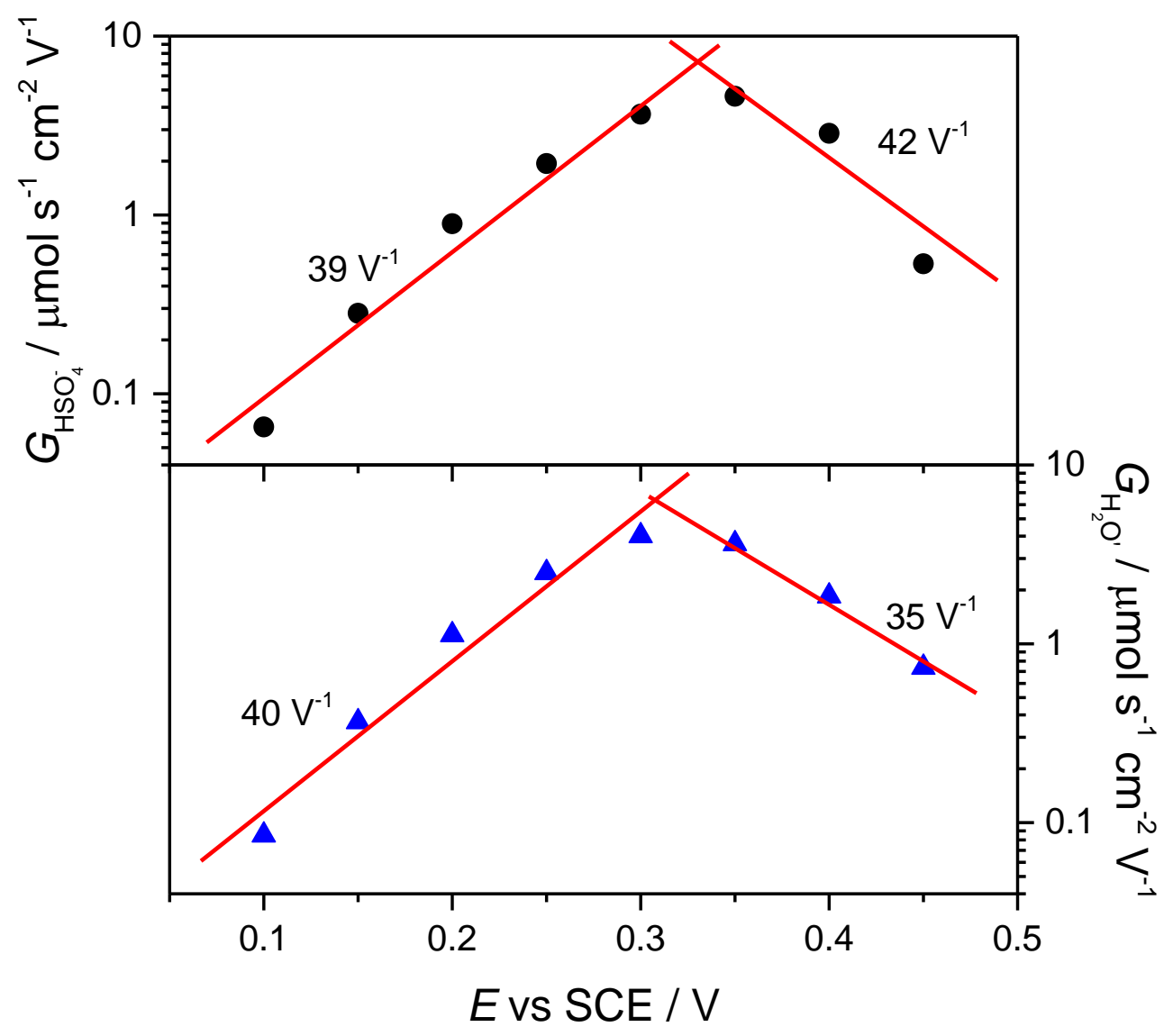

Figure 8 


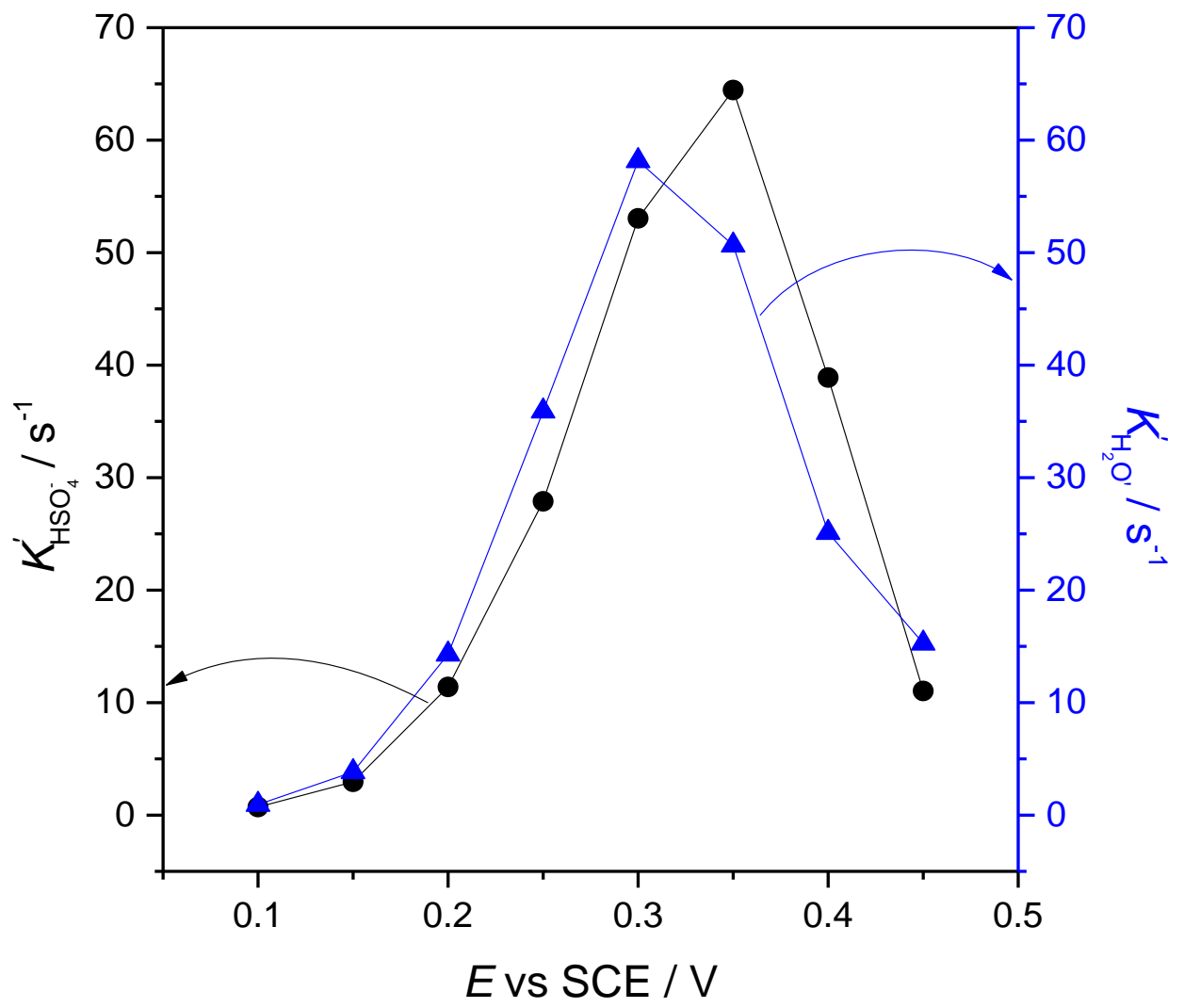

Figure 9 